\title{
CAMA
}

Centre for Applied Macroeconomic Analysis

\section{Evaluating the Portfolio Rebalancing Hypothesis in the Presence of the International Goods Market}

\section{CAMA Working Paper 85/2019 November 2019}

Kate McKinnon

Centre for Applied Macroeconomic Analysis, ANU

\begin{abstract}
A relatively recent approach to examining the currency-equity return relationship argues that the portfolio rebalancing activities of investors gives rise to an Uncovered Equity Parity condition (UEP), whereby higher relative equity returns in one country are associated with a currency depreciation as international investors re-jig positions to maintain optimal portfolio targets. Motivated by evidence that the UEP does not hold for large commodity exporters of Australia, Canada and New Zealand, this paper examines the impact the commodity market has on the currency and equity market interaction by applying a latent factor model designed to distinguish between comovement and spillovers. In order to contextualise the results, the same model is estimated for a sample of three benchmark OECD countries comprising Denmark, Sweden and the United Kingdom. The evidence is not supportive of the UEP for either country group, and there is particularly strong evidence of positive feedback between currency and equity markets for the benchmark OECD group. More generally, there are significant interconnections between all three asset markets for both the large commodity exporters and the benchmark OECD countries. This is unsurprising given that commodity prices play a role in transmitting demand and supply shocks to asset markets, and are also increasingly connected to traditional asset markets as a result of evolving investor behaviour.
\end{abstract}




\section{Keywords}

Exchange rates, commodity prices, stock prices, commodity currencies

JEL Classification

C38, F31, F41, G15

Address for correspondence:

(E) cama.admin@anu.edu.au

ISSN 2206-0332

The Centre for Applied Macroeconomic Analysis in the Crawford School of Public Policy has been established to build strong links between professional macroeconomists. It provides a forum for quality macroeconomic research and discussion of policy issues between academia, government and the private sector.

The Crawford School of Public Policy is the Australian National University's public policy school, serving and influencing Australia, Asia and the Pacific through advanced policy research, graduate and executive education, and policy impact. 


\title{
Evaluating the Portfolio Rebalancing Hypothesis in the Presence of the International Goods Market*
}

\author{
Kate McKinnon \\ Centre for Applied Macroeconomic Analysis, Crawford School of Public \\ Policy, Australian National University
}

November 2019

\begin{abstract}
A relatively recent approach to examining the currency-equity return relationship argues that the portfolio rebalancing activities of investors gives rise to an Uncovered Equity Parity condition (UEP), whereby higher relative equity returns in one country are associated with a currency depreciation as international investors re-jig positions to maintain optimal portfolio targets. Motivated by evidence that the UEP does not hold for large commodity exporters of Australia, Canada and New Zealand, this paper examines the impact the commodity market has on the currency and equity market interaction by applying a latent factor model designed to distinguish between comovement and spillovers. In order to contextualise the results, the same model is estimated for a sample of three benchmark OECD countries comprising Denmark, Sweden and the United Kingdom. The evidence is not supportive of the UEP for either country group, and there is particularly strong evidence of positive feedback between currency and equity markets for the benchmark OECD group. More generally, there are significant interconnections between all three asset markets for both the large commodity exporters and the benchmark OECD countries. This is unsurprising given that commodity prices play a role in transmitting demand and supply shocks to asset markets, and are also increasingly connected to traditional asset markets as a result of evolving investor behaviour.
\end{abstract}

Keywords: Exchange rates, commodity prices, stock prices, commodity currencies

JEL Classification Numbers: C38, F31, F41, G15

*The author's email address is: kate.mckinnon@anu.edu.au. I thank Professor Renée McKibbin for valuable guidance. 


\section{Introduction}

This paper is related to models of international portfolio choice and is concerned with the implications that the international trade in goods has for asset pricing and the interconnectedness of returns. The reference point for the analysis in this paper is the Uncovered Equity Parity model (UEP) of Hau and Rey (2006), which is a portfolio rebalancing model that predicts bidirectional links between currency and equity returns are generated through capital flows initiated by international investors who seek to maintain target portfolio holdings in the face of asset price fluctuations. A key empirical implication of the UEP is negative feedback between the value of the exchange rate and the stock market, and simple correlation analysis performed on the Hau and Rey (2006) sample bears this prediction out for the majority of OECD countries. A notable exception is Australia and it is suggested that this may be due to its reliance on primary commodity exports since this is a key distinguishing characteristic of the country, however the Hau and Rey (2006) model abstracts from the goods market. Studying an expanded group of commodity exporting countries with 'commodity currencies' in response to this observation, Chaban (2009) confirms that equity and currency returns comove positively for Australia, Canada and New Zealand. In connection to these studies, a key objective of this paper is to explore how world commodity prices affect the relationship between currency and equity markets for large commodity exporters.

There is a wealth of theoretical and empirical literature on the currency - equity market relationship, and no consensus in either area; not only do theoretical models predict opposite dynamics in the feedback between equity and currency returns and posit a variety of mechanisms underlying the relationship, but empirical analysis applying methods of varying complexity in an attempt to uncover the relationship do not produce consistent answers. Cross-market linkages between asset markets may be due to comovement or spillover effects, and for the former case it difficult to make assertions regarding the transmission mechanism. The analysis in this paper utilises a methodological framework which allows the magnitude and direction of transmission between markets to be explored. Specifically, the empirical model used is the latent factor model as the approach is ideologically consistent with models of joint asset price determination and can be extended to allow for spillover effects between asset markets in which prices are endogenously determined so that dynamic linkages can be better pinned down. The commodity market is included alongside the equity and currency 
market in order to determine the extent to which the goods market affects the interdependence between asset market returns. Unlike in Chaban (2009), commodity prices are treated as endogenous. Each return series are specified as a function of a common factor that affects all returns, an asset market return factor that affects only returns belonging to a particular asset class, and an idiosyncratic factor that is specific to an individual series. Additionally, each return series is described as a function of cross-market lagged asset market factors representing spillover effects.

Where Hau and Rey (2006) only include the one commodity country of Australia in the OECD sample used, Chaban (2009) narrows focus to examine the three commodity countries in isolation. To better facilitate comparison of the cross-market transmission mechanisms between country groups, the same latent factor model is estimated using monthly data for the three commodity currency countries of Australia, Canada and New Zealand and three non-commodity currency OECD countries of Sweden, the United Kingdom and Denmark. Preliminary data analysis helped inform the selection of the OECD countries to be used as a benchmark, with inclusion according to a number of criteria: the correlation between excess equity returns and currency returns is in accordance with the UEP; the countries have not adopted the Euro; and the countries are not classified as big primary commodity exporters. While this enables inferences regarding the uniqueness of the large commodity exporting countries in respect to asset market interactions to be made, there is a rationale for incorporating a role for the commodity market in empirical models of currency and equity returns more generally, since it is well established that equity, currency and commodity markets are integrated through global trade and financial flows. Demand and supply shocks are transmitted through international asset markets by commodity prices, and commodity prices are becoming increasingly subject to spillovers from other financial asset classes due to the huge growth in institutional funds flowing to commodity indices since the early to mid 2000s.

Currency and equity indices for each of the 6 countries are used as well as five categories of world commodity prices: agricultural raw materials; beverages; food; metals; and oil. Two samples periods are used: one running from 1982 to the end of 1999 and one beginning in 2000 and ending in 2016. Evidence in Hau and Rey (2006) as well as Chaban (2009) suggests that the direction of the correlation between equity and currency for the commodity countries changes to become negative when using a sample period starting after 2000. More generally, the period beginning circa early 
2000 is typically taken in the literature to mark the onset of the 'financialisation of commodities', which refers to the treatment of commodities as a financial asset class by portfolio investors (for instance, see: Cheng and Xiong, 2013; Erb and Harvey, 2006; Gorton and Rouwenhorst, 2006). Examining how spillovers between the three asset markets compare over sub-samples is also interesting in this context.

The results obtained from estimating the model with the commodity exporters are not supportive of the UEP in either sample, though the evidence becomes weaker over the more recent sample. For the model estimated for the large commodity exporters, a shock in the equity market that causes gains in equity returns for all three countries does lead to a depreciation in the currencies of those countries' currencies over the pre 2000 sample period however the direction of currency market spillovers to equity returns implies that a shock which appreciates the currencies has a positive effect on equity returns in the next period, which is not consistent with the UEP. It is more difficult to make generalisations in the post 2000 sample as the effect of currency and equity market spillovers on cross-market individual returns is more mixed across the countries. Interestingly, when the same model is estimated for the three other OECD countries, the results are generally weaker when considered in the context of the UEP; in both sample periods a shock in the equity market that causes gains in equity returns typically appreciates the next period currency returns and a positive shock across all currency markets subsequently drives up equity returns in the early sample, though the direction of impact is mixed in the recent sample.

The results from estimating the benchmark model with the three non-large commodity exporting OECD countries reveal that commodity market spillovers to the currency and equity returns of these countries are important. This suggests that it is not only pertinent to consider the role of commodity markets in asset price determination for the notably large commodity exporting countries. While the sample of countries is limited, the results suggest that there is an interconnectedness of the currency, equity and commodity markets for both groups of countries, and that a model which examines the relationship of only a subset of the markets will not fully capture the dynamics of the relationships.

The remainder of the paper proceeds as follows. Section 2 summarises literature related to the currency and equity return relationship as well the interaction between these assets and commodity prices. Section 3 outlines the latent factor model used to investigate the UEP while allowing for commodity price linkages. Section 4 is comprised 
of preliminary data analysis that tests the correlation results found by Hau and Rey (2006) using an expanded sample of commodity exporting countries and extends the currency and equity correlation analysis to world commodity price returns. Section 5 presents the results from estimating the factor models for both the large commodity exporting countries and the benchmark OECD country group. Section 6 concludes.

\section{The UEP and Related Literature}

The central empirical prediction of Hau and Rey (2006) is that an outperformance of a country's equity market relative to the foreign equity market is associated with a depreciation of the domestic currency against the foreign currency. The model was motivated by the empirical failure of the traditional macro-based exchange rate determination models and capitalised instead on a burgeoning literature demonstrating that stock market 'order flow' (the difference of buyer over seller initiated trades in the foreign exchange market) is highly correlated with the exchange rate.

The theoretical model is a micro founded equilibrium model wherein relative equity prices, capital flows and exchange rates between two countries are jointly determined as an outcome of optimising international investment behaviour. The model predictions are underpinned by additional assumptions on investor and market characteristics, chief among these is that there is less than perfect price elasticity of forex supply and risk averse investors. Importantly, incomplete forex risk trading is built into the model through a ban on the short sale of foreign bonds in order to reflect survey evidence that reports a low incidence of risk hedging in forex trading. ${ }^{1}$

The implication for the representative investor is that they cannot unbundle exchange rate and equity risks and so will factor both the volatility of the exchange rate as well as the correlation structure of exchange rates and foreign equity returns into their optimal portfolio investment decision. To illustrate the ramifications of this in terms of the decision making process of agents, the chain of events explicated in the model in response to a negative equity price shock in the foreign market can be distilled as follows: i) an unexpected negative shock (in the form of an exogenous dividend innovation) to the foreign equity market decreases the share of foreign equity in the portfolio; ii) the exposure to forex risk decreases; iii) investors reallocate their port-

\footnotetext{
${ }^{1}$ A study by Levich et al. (1998) is cited to justify this feature. The authors found that forex risk hedging was done on only $8 \%$ of the total foreign equity investment. Portfolio managers interviewed cited monitoring problems, lack of knowledge, and public and regulatory perceptions as reasons.
} 
folios to increase foreign equity holdings in response, instigating forex order flow; iv) the forex order flow (because of less than perfect supply elasticity) results in a foreign currency appreciation.

This dynamic portfolio rebalancing story highlights a couple of key implications which can be extracted from the theoretical model and confronted with data to speak to their validity. First, exchange rate returns and excess equity returns are negatively correlated. Second, exchange rate returns and equity flows are positively correlated. The focus is on exchange rate volatility in the short and medium term, so the model abstains from considering the goods market. This marks a significant departure from traditional portfolio balance models that assume a long run Purchasing Power Parity (PPP) condition holds for exchange rate determination.

Using monthly data on United States (US) dollar denominated exchange rates and excess equity returns, measured as local country returns compared to US returns, for a set of OECD countries over the period January 1990 to December 2001, Hau and Rey (2006) find a negative correlation between relative equity returns and exchange rate returns for all countries except Australia and Japan. A notable distinguishing feature of Australia is its status as a large primary commodity exporter, thus it is perhaps unsurprising that a generalised model describing the joint interaction between equity flows, equity returns and currency returns which omits trade in goods does not apply to a large commodity exporter. Since Australia was the sole country in the sample of Hau and Rey (2005) that could be described as having a 'commodity currency', their results could not be extrapolated to make any statements about the applicability of UEP for commodity exporters more generally. ${ }^{2}$

Chaban (2009) explored this particular conjecture, specifically testing whether the relationship between currency and equity returns were in line with the portfolio rebalancing story for Australia, New Zealand and Canada using a variety of empirical techniques comprising: simple correlation structures; regression analysis that controls for commodity prices; and a Structural Vector Autoregression model (SVAR) with sign restrictions identifying structural shocks to equity and currency returns chosen to bias findings in favour of the portfolio rebalancing model. Overall, the evidence was not consistent with the UEP, although the equity - currency return correlation becomes negative over a sample period starting in 2000. Impulse response functions

\footnotetext{
${ }^{2}$ Amongst OECD countries that Hau and Rey (2006) identified as candidates for analysis, New Zealand was excluded due to data availability issues and Canada was excluded based on its purported practical pegging of the Canadian dollar to the USD.
} 
demonstrate that a positive shock to commodity prices (interpreted to be a result of a positive supply shock) increases equity returns in both the US and commodity countries, arguably reducing the portfolio rebalancing motive, and also appreciates the commodity currencies.

The SVAR specified in Chaban (2009) models equity flows, exchange rates and equity returns as endogenous and imposes the assumption that commodity prices are exogenous to the equity markets and currencies of the commodity countries, yet this is a source of debate in the literature. While some empirical studies have found that commodity prices are exogenous in respect to the commodity currencies - for instance, Chen and Rogoff (2003) using a sample including Australia, Canada and New Zealand, and Amano and van Norden (1995) for the case of Canada - there are theoretical and empirical results which question this. ${ }^{3}$ Clements and Fry (2008) outline a theoretical model which demonstrates that a commodity currency can impact commodity prices if the country has sufficient market power. Specifically, the model predicts currency appreciations stemming from a commodity price boom compound initial price rises as producers make downward adjustments to output in the face of reduced profit margins. Ridler and Yandle (1972) develop a model which demonstrates that commodity prices may be influenced by countries' currency movements if those countries have sufficient market power even on a collective basis. Clements and Fry (2008) use a latent factor model of currency and commodity returns which allows for bidirectional feedback between the markets and find greater evidence of currency to commmodity spillovers than commodity to currency spillovers. Preliminary results from Granger causality analysis in that paper supported this contention. Chen et al. (2010) also found evidence that the exchange rates of Australia, New Zealand, Canada, South Africa and Chile Granger cause commodity prices.

The UEP model is a relatively recent approach; numerous theoretical models have sought to explain the interaction of stock and currency returns, whether approaching from a flow perspective, for instance, Dornbusch and Fisher (1980), or a stock perspective, for instance, the portfolio balance models of Branson (1983) and Frankel (1983). As with the UEP model, the empirical predictions regarding the correlation structure of

\footnotetext{
${ }^{3}$ Studies related to other countries which find a strong response of the exchange rate to commodity prices include Ricci et al. (2016), for a panel of 48 countries and Cashin et al. (2004) for a set of 58 developed and developing countries, although the latter finds a significant long run elasticity for less than half the sample countries; for a fair number of countries Cashin et al. (2004) cannot discount the proposition that there are feedback effects running both ways.
} 
equity and currency returns that are outputs of the models are binary. Simple correlation analysis demonstrating a positive or negative comovement could be more credibly employed to dispute the veracity of a theory based on its empirical predictions than it can be used to justify it. In addition, investigating the ostensible relationship gives little insight into the underlying mechanism at work. By utilising a latent factor model where equity, commodity and currency returns are jointly determined, the effects of the direct spillovers from the asset markets can be isolated and disentangled from the common noise inherent in asset price movements.

There is a relatively large literature on the stock - commodity price interaction, and attempts characterise the relationship between commodity prices and stock markets have intensified throughout the 2000s. Research applying conditional correlation models have found increased comovement in volatility and prices levels between commodity prices and stock indices that was amplified during the financial crisis (see, for instance, Creti et al., 2013, and Mensi et al., 2013, for studies related to the US). The increased connection between stocks and commodities is relatively new, for instance, Gorton and Rouwenhorst (2006) note there was low correlation between commodity prices and stocks prior to 2000 .

Some of this literature is couched in the context of the huge inflows of investor funds into commodity indices traditionally used by producers to hedge price risk. Tang and Xiong (2012) date this so called financialisation of commodities to 2004. Cheng and Xiong (2014) assert that commodities are increasing being treated as an asset class alongside stocks and bonds by institutional investors who typically trade commodity futures. There is some debate as to whether this integration translates to spot prices and the extent to which these are then influenced by speculation. For instance, Kilian and Murphy (2014) find evidence that the world oil price surge in the years preceding the financial crisis stemmed from business cycle related demand shocks as opposed to speculation, and Mensi et al. (2016) similarly rule out speculation as a driver price runs in the spot prices of oil, coffee and cocoa. However, Basak and Pavlova (2016) outline a theoretical model of financialisation in which stock prices and commodity futures prices spillover to the spot price provided the underlying commodity is storable. The implication is that on index commodity prices are more subject to common shocks, and evidence in support of this is found by Tang and Xiong (2012). Silvennoinen and Thorp (2013) contend that the integration of commodity markets with other asset markets will result in common shocks play a growing role in driving commodity returns. The 
use of commodity futures as an investment vehicle also implies that spillovers between markets occur as a result of portfolio risk management and diversification.

The focus on the relationship between commodity and stock markets has evolved partly in concert with the effort to analyse the connection between financial asset prices and the economy, since commodity prices propagate demand and supply shocks through the domestic and international real sector. Kang et al. (2017) find that there is bidirectional feedback between global stock price volatility and commodity prices whereby increased stock volatility depresses commodity prices, and growth in commodity prices increase stock volatility. The endogeneity between the commodity and stock market stems from the links each has to output and inflation. Kilian and Park (2009) demonstrate that demand and supply shocks transmuted through oil market shocks account for $22 \%$ of variability in stock returns in the US. Pavlova and Rigobon (2007) outline a theoretical asset pricing model in which terms of trade movements transits demand and supply shocks across international asset markets.

While the model in this paper is adopted to reflect the portfolio rebalancing model while allowing for transmission of shocks through the goods market, the results of the model estimation are viewed in the context of a wider literature which typically focuses on bivariate relationships between currency, equity and commodity markets, in order to speak to comovement and spillovers between all three markets.

\section{The Econometric Framework}

This section outlines the empirical framework used to explore whether the dynamic interactions between currency returns and equity returns are in line with the predictions of the Uncovered Equity Parity (UEP) model of Hau and Rey (2006) while incorporating a role for commodity markets in the joint determination of the currency and equity returns.

The latent factor framework is adopted to analyse the interactions between asset markets of the sample countries. Latent factor models attribute comovement among time series variables to of a limited number of unobserved factors common to the observable series. ${ }^{4}$ The factor structure is designed to allow for dynamics between

\footnotetext{
${ }^{4}$ Factor models were traditionally applied to studies on the nature of national and international business cycles, and it has been shown in many studies that two or three factors can sufficiently capture a significant amount of the variation in macroeconomic variables (for instance, Sargent and Sims, 1977). However these models have also been utilised since the 1990s to examine behaviour of currency, equity and interest rates. For instance, for studies related to exchange rates see Ng et al.
} 
variables that are informed by pre-established hypotheses regarding the relationship between them. A major advantage of the model is that it doesn't require explicit identification of relevant observable independent variables, nor entail the associated modelling of the relationship these have with the dependent variables. This is useful for asset return models in practice as it is challenging to observe all the variables affecting returns and a failure to capture a comprehensive set of drivers may obscure existing links between markets.

In this case, currency, and equity returns for a set of countries and world commodity price returns are specified to be jointly determined by a set of unobservable factors: a common factor which affects all countries and asset markets; a commodity currency returns factor, common to the currencies of the commodity exporting countries; a commodity price factor, which is common to the commodity returns; an equity market factor, common to the equity market returns; and idiosyncratic factors, which are unique to each individual asset market return in each country. The identification of the market factors enables the modelling of spillovers through the inclusion of lagged cross-asset market factors in each returns' specification in order to explore inter-connectedness. The model is consistent with the UEP, as the latent factors are designed to encapsulate all cross-correlation between the return series and isolate feedback effects, and has the advantage of not imposing an assumption that commodity prices are exogenous.

Since the evidence suggests that the portfolio rebalancing mechanism is interrupted for the large commodity exporting countries, a model using the currency and equity returns for the three large commodity exporters of Australia, Canada and New Zealand is estimated. However, in order to facilitate the ability to draw inferences regarding the peculiarity of the interaction of the asset markets of these countries, an analogous model is estimated for three OECD countries and used as a benchmark or base case. Preliminary correlation analysis is conducted in order to select OECD countries to use in this benchmark model

In both the models of large commodity exporters and benchmark OECD countries, the US equity market return is included in order to help pin down the common factor. US equity returns are specified as a function of the common factor and an idiosyncratic factor. The US currency is implicitly included as the US dollar is the numeraire

(1992), Diebold and Nerlove (1989), Dungey (1999), and for models focusing on international financial market contagion see Dungey et al. (2004), and Dungey et al. (2006). 
currency.

\subsection{Currency Returns Specification}

Currency returns, $C$, are specified as follows

$$
C_{i, t}=\lambda_{i} V_{t}+\varphi_{i} C F_{t}+\beta_{i} P F_{t-1}+\theta_{i} E F_{t-1}+\sigma_{i} U_{i, t}, \quad i=1, \ldots, m
$$

where $i$ is the country index for the $i=3$ currency return variables, $V$, is the common factor that affects returns of all asset markets in all countries, $C F$ is the currency market factor that affects only currency returns, and $U$ captures idiosyncractic variation in each series. The lagged asset market factors extracted from the commodity and equity returns specifications are included and denoted by $P F_{t-1}$ and $E F_{t-1}$ respectively. The impact of the common factor, currency factor, lagged commodity factor, lagged equity factor, and the idiosyncratic factor on the currency returns are captured by the factor loadings $\lambda, \varphi, \beta, \theta$ and $\sigma$, respectively.

\subsection{Commodity Returns Specification}

World commodity price returns, $P$, are specified as follows

$$
P_{j, t}=\lambda_{j} V_{t}+\delta_{j} P F_{t}+\gamma_{j} C F_{t-1}+\theta_{j} E F_{t-1}+\sigma_{j} U_{j, t}, \quad j=1, \ldots, v
$$

where $j$ is the sub-category index for the $v=5$ commodity return categories, $P F_{t}$ is the commodity factor and $C F_{t-1}$ is the lagged currency market factor.

\subsection{Equity Returns Specification}

Equity returns, E, are specified as follows

$$
E_{k, t}=\lambda_{k} V_{t}+\kappa_{k} E F_{t}+\gamma_{k} C F_{t-1}+\beta_{k} P F_{t-1}+\sigma_{k} U_{k, t}, \quad k=1, \ldots, n
$$

where $k$ is the country index for the $n=3$ equity returns variables, $E F_{t}$, is the equity market factor that affects all equity returns.

\subsection{US Equity Returns Specification}

The US equity return is a function of the common factor and an idiosyncratic factor

$$
E_{U S, t}=\lambda_{U S} V_{t}+\sigma_{U S} U_{U S, t} .
$$




\subsection{Factor Specification}

The common factor, the commodity price return factor, the currency return factor and the equity return factor are specified as $\mathrm{AR}(1)$ processes

$$
\begin{gathered}
V_{t}=\rho_{V} V_{t-1}+\epsilon_{V, t}, \\
C F_{t}=\rho_{C F} C F_{t-1}+\epsilon_{C F, t}, \\
P F_{t}=\rho_{P F} P F_{t-1}+\epsilon_{P F, t}, \\
E F_{t}=\rho_{E F} E F_{t-1}+\epsilon_{E F, t},
\end{gathered}
$$

where the lag length was informed by the Akaike Information Criteria (AIC), which selected one lag order as optimal for characterising the system as whole. The lag order selection tests for both the commodity country group and the benchmark OECD country group are reported in Appendix A. The idiosyncratic factors are assumed to be a function of a white noise process only, as follows

$$
U_{l, t}=\eta_{l, t}
$$

where $l=C_{1}, C_{2}, C_{3}, P_{1}, P_{2}, P_{3}, P_{3}, P_{4}, P_{5}, E_{1}, E_{2}, E_{3}, E_{U S}$

\subsection{The Complete Factor Model}

The measurement equations in (1) through (4), which describe the relationship between the return series and the latent factors, can be summarised in matrix form as follows

$$
Y_{t}=\Lambda F_{t}+W_{t}
$$

where $Y_{t}$ is the $x \times 1$ column vector of return series observed at time $t ; F_{t}$ is the $m \times 1$ vector of latent factors; $\Lambda$ is the $x \mathrm{x} m$ matrix of factor loadings which link the return variables to the factors; and $W_{t}$ is a $x \times 1$ vector of errors. In this case, $x=12$ and $m=19$.

The transition equations in (5) through (9), which describe the dynamics of the latent factors, can be summarised in matrix form as

$$
F_{t}=\Delta F_{t-1}+\Sigma_{t}
$$

where $F_{t-1}$ is the $m \mathrm{x} 1$ vector of autoregressive factors, and $\Delta$ is the $m \mathrm{x} m$ matrix of parameter loadings on the autoregressive factors and $n_{t}$ is a $m \times 1$ column vector of the disturbance terms. 
The error matrices for the matrix of measurement equations, $W_{t}$ and transition equations, $\Sigma_{t}$, are vectors of white noise processes such that

$$
\begin{aligned}
& E\left(W_{t} W_{\pi}^{\prime}\right)=\left\{\begin{array}{ll}
R & \text { for } t=\pi \\
0 & \text { otherwise }
\end{array},\right. \\
& E\left(\Sigma_{t} \Sigma_{\pi}^{\prime}\right)= \begin{cases}Q & \text { for } t=\pi \\
0 & \text { otherwise }\end{cases}
\end{aligned}
$$

In this case, $W_{t}=0$ since the idiosyncratic components in the returns are treated as factors so that this component of return volatility can be analysed along with the common factors, and so $R_{t}=0 .^{5}$ For identification purposes, the restriction is imposed that the variance covariance of (11) is the identity matrix, $Q=I$, so that the error matrix reflects the assumption that the factors are independent of each other.

To illustrate how zero restrictions in the factor loading matrix are used to identify hierarchical factors and spillovers by specifying the factors that each variable loads on to, the elements of equation (10) are written out in full matrix form, as follows

$$
Y_{t}=\left[\begin{array}{c}
C_{1, t} \\
C_{2, t} \\
C_{3, t} \\
P_{1, t} \\
P_{2, t} \\
P_{3, t} \\
P_{4, t} \\
P_{5, t} \\
E_{1, t} \\
E_{2, t} \\
E_{3, t} \\
E_{U S, t}
\end{array}\right], \quad F_{t}=\left[\begin{array}{c}
V_{t} \\
C F_{t} \\
P F_{t} \\
E F_{t} \\
U_{C_{1}, t} \\
U_{C_{2}, t} \\
U_{C_{3}, t} \\
U_{P_{1}, t} \\
U_{P_{2}, t} \\
U_{P_{3}, t} \\
U_{P_{4}, t} \\
U_{P_{5}, t} \\
U_{E_{1}, t} \\
U_{E_{2}, t} \\
U_{E_{3}, t} \\
U_{E_{U}, t} \\
P F_{t-1} \\
C F_{t-1} \\
E F_{t-1}
\end{array}\right], \quad u_{C_{1}, t}=\left[\begin{array}{l}
0 \\
0 \\
0 \\
0 \\
0 \\
0 \\
0 \\
0 \\
0 \\
0 \\
0 \\
0
\end{array}\right],
$$

\footnotetext{
${ }^{5}$ Alternatively, there is a disturbance term in the measurement equation.
} 
and

$$
\begin{aligned}
& \Lambda= \\
& {\left[\begin{array}{ccccccccccccccccccc}
\lambda_{C_{1}} & \varphi_{C_{1}} & 0 & 0 & \sigma_{C_{1}} & 0 & 0 & 0 & 0 & 0 & 0 & 0 & 0 & 0 & 0 & 0 & \beta_{C_{1}} & 0 & \theta_{C_{1}} \\
\lambda_{C_{2}} & \varphi_{C_{2}} & 0 & 0 & 0 & \sigma_{C_{2}} & 0 & 0 & 0 & 0 & 0 & 0 & 0 & 0 & 0 & 0 & \beta_{C_{2}} & 0 & \theta_{C_{2}} \\
\lambda_{C_{3}} & \varphi_{C_{3}} & 0 & 0 & 0 & 0 & \sigma_{C_{3}} & 0 & 0 & 0 & 0 & 0 & 0 & 0 & 0 & 0 & \beta_{C_{3}} & 0 & \theta_{C_{3}} \\
\lambda_{P_{1}} & 0 & \delta_{P_{1}} & 0 & 0 & 0 & 0 & \sigma_{P_{1}} & 0 & 0 & 0 & 0 & 0 & 0 & 0 & 0 & 0 & \gamma_{P_{1}} & \theta_{P_{1}} \\
\lambda_{P_{2}} & 0 & \delta_{P_{2}} & 0 & 0 & 0 & 0 & 0 & \sigma_{P_{2}} & 0 & 0 & 0 & 0 & 0 & 0 & 0 & 0 & \gamma_{P_{2}} & \theta_{P_{2}} \\
\lambda_{P_{3}} & 0 & \delta_{P_{3}} & 0 & 0 & 0 & 0 & 0 & 0 & \sigma_{P_{3}} & 0 & 0 & 0 & 0 & 0 & 0 & 0 & \gamma_{P_{3}} & \theta_{P_{3}} \\
\lambda_{P_{4}} & 0 & \delta_{P_{4}} & 0 & 0 & 0 & 0 & 0 & 0 & 0 & \sigma_{P_{4}} & 0 & 0 & 0 & 0 & 0 & 0 & \gamma_{P_{4}} & \theta_{P_{4}} \\
\lambda_{P_{5}} & 0 & \delta_{P_{5}} & 0 & 0 & 0 & 0 & 0 & 0 & 0 & 0 & \sigma_{P_{5}} & 0 & 0 & 0 & 0 & 0 & \gamma_{P_{5}} & \theta_{P_{5}} \\
\lambda_{E_{1}} & 0 & 0 & \kappa_{E_{1}} & 0 & 0 & 0 & 0 & 0 & 0 & 0 & 0 & \sigma_{E_{1}} & 0 & 0 & 0 & \beta_{E_{1}} \gamma_{E_{1}} & 0 \\
\lambda_{E_{2}} & 0 & 0 & \kappa_{E_{2}} & 0 & 0 & 0 & 0 & 0 & 0 & 0 & 0 & 0 & \sigma_{E_{2}} & 0 & 0 & \beta_{E_{2}} & \gamma_{E_{2}} & 0 \\
\lambda_{E_{3}} & 0 & 0 & \kappa_{E_{3}} & 0 & 0 & 0 & 0 & 0 & 0 & 0 & 0 & 0 & 0 & \sigma_{E_{3}} & 0 & \beta_{E_{3}} & \gamma_{E_{3}} & 0 \\
\lambda_{E_{U S}} & 0 & 0 & 0 & 0 & 0 & 0 & 0 & 0 & 0 & 0 & 0 & 0 & 0 & 0 & \sigma_{E_{U S}} & 0 & 0 & 0
\end{array}\right] .}
\end{aligned}
$$

In full matrix form equation (11) is expanded as follows

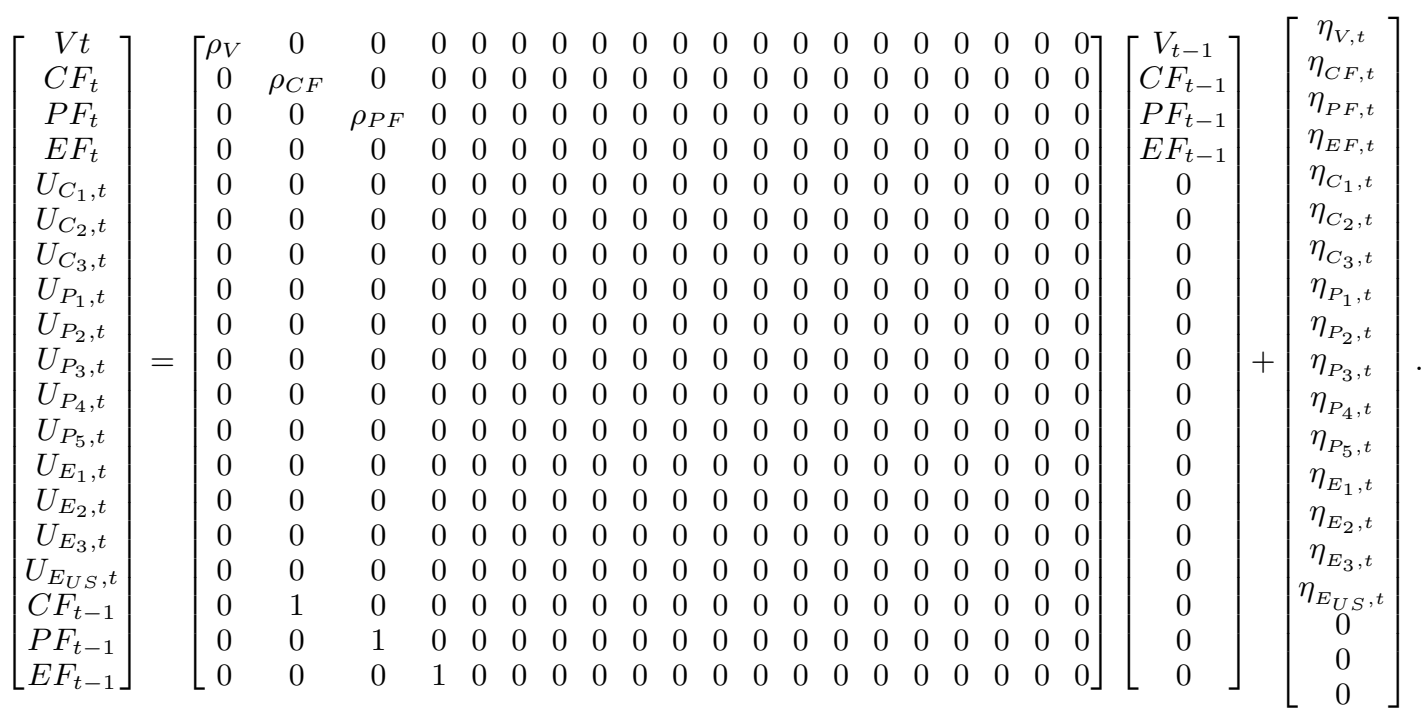

The complete factor model is estimated by directly using the Kalman filter, with the parameters estimated by maximum likelihood (MLE). ${ }^{6}$ The procedure can be thought of broadly as involving two steps. First, the parameters of the latent factor model are estimated through MLE; and, second, conditional on these parameter estimates, the Kalman filter is used to extract the factors.

\subsection{Assessing the Importance of Spillovers}

The central focus of the model testing is to ascertain the importance of the asset market spillover channels. This is done through two means: assessment of the magnitude of

\footnotetext{
${ }^{6}$ For details on the Kalman filter algorithm see Hamilton (1994, Chapter 13).
} 
spillovers in terms of the volatility contribution they make to returns; and hypothesis testing to determine whether the parameters attached to spillovers are non-zero.

The assumption that factors are independent enables the interpretation of results in terms of the proportionate contribution each factor makes to the overall volatility of each asset. For each asset market, the relative contribution of the factors to return volatility is found by squaring both sides of the specifications in equations (1), (2), and (3) and taking expectations. For instance, in the case of the currency returns this implies

$$
E\left[C_{i, t}^{2}\right]=\frac{\lambda_{i}^{2}}{1-\rho_{V}^{2}}+\frac{\gamma_{i}^{2}}{1-\rho_{C F}^{2}}+\frac{\beta_{i}^{2}}{1-\rho_{P F}^{2}}+\frac{\theta_{i}^{2}}{1-\rho_{E F}^{2}}+\sigma_{i}^{2}, \quad i=1, \ldots, m
$$

where $\frac{\lambda_{i}^{2}}{1-\rho_{V}^{2}}$ is the contemporaneous contribution of the common factor to currency return volatility, $\frac{\gamma_{i}^{2}}{1-\rho_{C F}^{2}}$ is the contribution of the currency market factor, $\frac{\beta_{i}^{2}}{1-\rho_{P F}^{2}}$ and $\frac{\theta_{i}^{2}}{1-\rho_{E F}^{2}}$ are the shares of volatility accounted for by the lagged commodity and equity market factors respectively, and $\sigma_{i}^{2}$ is the volatility due to the idiosyncratic factor specific to the series.

Apart from the relative magnitude of the cross-market spillovers, the following hypotheses regarding the joint significance of the factor loadings on the lagged asset market factors are outlined and tested:

Hypothesis 1: No spillovers from the currency market

$H_{o}: \gamma_{i}=\gamma_{k}=0$

Hypothesis 2: No spillovers from the commodity market

$H_{o}: \beta_{i}=\beta_{k}=0$

Hypothesis 3: No spillovers from the equity market

$H_{o}: \theta_{i}=\theta_{j}=0$

Hypothesis 4: No spillovers from the commodity or currency market

$H_{o}: \gamma_{i}=\gamma_{k}=\beta_{i}=\beta_{k}=0$

Hypothesis 5: No spillovers from the equity or commodity market

$H_{o}: \beta_{i}=\beta_{k}=\theta_{i}=\theta_{j}=0$

Hypothesis 6: No spillovers from the currency or equity market

$H_{o}: \gamma_{i}=\gamma_{k}=\theta_{i}=\theta_{j}=0$

Hypothesis 7: No spillovers from the currency, equity or commodity market

$H_{o}: \gamma_{i}=\gamma_{k}=\beta_{i}=\beta_{k}=\theta_{i}=\theta_{j}=0$

A joint test of each null hypothesis is conducted using the likelihood ratio (LR) 
test. Under the null hypothesis, the LR statistic is

$$
2[L(\hat{\theta})-L(\tilde{\theta})] \sim \chi^{2}(m) .
$$

where $L(\hat{\theta})$ denotes the value of the unrestricted log likelihood function, $L(\tilde{\theta})$ denotes the value of the restricted log likelihood function. The LR statistic has a Chi squared distribution with $m$ degrees of freedom equal to the number of restrictions.

\section{The Data, Sample and Preliminary Analysis}

This section presents results of preliminary data analysis in the form of correlation analysis for a wider group of OECD countries and describes the data and sample used for this purpose. The goal of the preliminary data analysis in this section is to reexamine the results of Hau and Rey (2006) pursuant to a few objectives: 1) to check the sensitivity of the correlation evidence supporting the portfolio balancing model to the data construction; 2) to explore the inferences made by Hau and Rey (2006) regarding the anomalous status of large commodity exporters using an expanded sample of commodity exporting countries; 3) to investigate the correlation between commodity returns and the currency and excess equity returns; and 4) to inform the selection of the sample of OECD countries to be used the latent factor model estimations. The return data used for the preliminary analysis is then used for to estimate the model outlined in Section 3, however only three non-commodity exporting OECD countries are required for use in a benchmark model.

\subsection{Data and Sample}

Exchange rate data is compiled by the International Monetary Fund (IMF) and published through the International Financial Statistics (IFS) database. It is expressed as US dollar per national currency unit, so that an increase in the exchange rate represents an appreciation of the local currency. The IMF IFS divides global commodity price indices into five categories: agriculture; beverages; food; metals; and energy. These sub-indices, published in US dollar terms, comprise the data from which commodity price returns are extracted, though the sub-index for oil is used to proxy for the energy sub-index since the latter has been published only since 1992. Country specific end of day equity price indices are compiled by Morgan Stanley Capital International (MSCI). The MSCI Index is designed to measure the performance of the large and mid-cap segments of each country's market, covering approximately $85 \%$ of the free float-adjusted 
market capitalization. Following Hau and Rey (2006) and Chaban (2009), nominal variables are used.

Hau and Rey (2006) test correlations using daily, monthly and quarterly data, but find the most evidence in support of portfolio rebalancing activities using monthly data, which is the format used here. While Hau and Rey (2006) use end of period returns, the use of period average returns for the analysis here is necessitated by the practicality that world commodity prices are published exclusively as period average indices over the sample period. ${ }^{7}$ While restricted by this availability issue, it seems reasonable that focusing on period average equity and currency indices may provide a more comprehensive picture of the relationship between returns over a given period. Using an arbitrary end of period snapshot of the prices for volatile return series may not sufficiently characterise the true correlations of the variables. In fact, for this same reason, investors engaged in portfolio rebalancing activites at regular intervals (such as monthly or quarterly) could reasonably be expected to consider the price dynamics over the period rather than by using a snapshot comparison between period end dates.

The end of day MSCI equity index is converted to a period average using arithmetic averaging in line with the methodology used for construction of the commodity and exchange rate period average indices. For each series, returns are calculated by taking $\log$ differences of the nominal average price index. Finally, for the purposes of the correlation analysis the excess equity return is calculated by subtracting the US monthly average equity return from the local monthly equity return. All data used in the analysis is sourced through Thomson Reuter's DataStream. Detailed definitions and source information is contained in Appendix B.

The sample of countries used for the preliminary correlation analysis is based on that used in the empirical analysis of Hau and Rey (2006), which comprised OECD members on the basis that these countries have the most evolved equity markets. Of the 24 OECD countries which were members at the start of the sample period (i.e. as at 1st January, 1980), 18 of these are used in the Hau and Rey (2006) analysis. ${ }^{8}$ The United States is taken as the home country against which the foreign equity returns are measured since it is the largest conduit for international equity flows, leaving 17 countries in the sample in which to test the practical predictions of the UEP.

Hau and Rey (2006) use a sample period spanning January 1980 to December 2001.

\footnotetext{
${ }^{7}$ Currency-equity correlations using both formats are compared in an exercise not reported on here to ensure results are not too dissimilar.

${ }^{8}$ Belgium and Luxembourg are included as one country.
} 
Since the New Zealand equity index is available from January 1982 the start date used here is rolled back to incorporate it. Canada is also added to the sample. Iceland Ireland, Portugal and Turkey are excluded on grounds of data availability, leaving 19 countries in total. Details regarding the full this of countries used by Hau and Rey (2006) and this paper are contained in Appendix B. The end of the sample is constrained by the availability of world commodity price series which was discontinued by IMF IFS in the first month of 2017. Return data is calculated for the period February 1982 to December 2016. Based on the evidence in Hau and Rey (2006) and Chaban (2009) which together imply that there is a shift in the currency - equity relationship for the commodity countries around the turn of the century, the entire sample period is broken into two sub-periods to allow for the relationships to change across time: the first spans February 1982 to December 1999; and the more recent period spans January 2000 to December 2016.

\subsection{Correlation Analysis}

The direction and significance of correlation coefficients for intra-country excess equity and currency returns are discussed in the context of the results in Hau and Rey (2006) and Chaban (2009). Bivariate correlations between each of these returns and world commodity price returns are also reported.

\subsubsection{Currency - Equity Return Correlation}

The correlation coefficients for excess equity returns and currency returns extracted from period average price indices displayed in Table 1. The focus is on determining whether the central prediction of the portfolio rebalancing model holds over the post 2000 period, and whether the delineation between commodity exporting countries and other OECD countries holds when the sample is extended to include Canada and New Zealand. Overall, the results from the preliminary data analysis are not as supportive of the UEP as the results reported by Hau and Rey (2006) using the earlier sample. A significant negative correlation is found for only 6 of the sample countries. However the results support the contention that the commodity countries are anomalous over this period; Australia, Canada, New Zealand and Japan are the only countries for which the correlation between the currency and excess equity return is significantly positive (at the $5 \%$ level for Australia and Canada, the 1\% level for New Zealand, and the $10 \%$ level for Japan). 
Table 1: Monthly Excess Equity - Currency Return Correlations

\begin{tabular}{lcc}
\hline & Feb 1982-Dec 1999 & Jan 2000- Dec 2016 \\
\hline Australia & $0.265^{* * *}$ & $-0.281^{* * *}$ \\
Canada & $0.208^{* * *}$ & 0.042 \\
New Zealand & $0.139^{* *}$ & $-0.203^{* * *}$ \\
Austria & -0.096 & $0.184^{* * *}$ \\
Belgium & 0.004 & -0.088 \\
Denmark & $-0.194^{* * *}$ & $-0.215^{* * *}$ \\
Finland & 0.073 & $-0.118^{*}$ \\
France & 0.007 & $-0.243^{* * *}$ \\
Germany & -0.077 & $-0.189^{* * *}$ \\
Italy & 0.019 & -0.015 \\
Japan & $0.134^{*}$ & $-0.397^{* * *}$ \\
Netherlands & $-0.239^{* * *}$ & $-0.376^{* * *}$ \\
Norway & $-0.131^{*}$ & $0.204^{* * *}$ \\
Spain & -0.007 & 0.062 \\
Sweden & $-0.299^{* * *}$ & $-0.176^{* *}$ \\
Switzerland & $-0.269^{* * *}$ & $-0.441^{* * *}$ \\
United Kingdom & $-0.176^{* * *}$ & $-0.440^{* * *}$ \\
\hline
\end{tabular}

Notes: The correlation of coefficient is reported for each country's monthly currency and excess equity return. $*, * *, * *$ indicate whether the coefficient is statistically different from zero at the $1 \%, 5 \%$ and $10 \%$ level, respectively.

Consistent with results in Chaban (2009) this anomaly dissipates as the sample period is moved back; the correlation between relative equity returns and currency returns for Australia and New Zealand is negative and significant over the recent sample, and while the coefficient for Canada is positive, it is no longer significant. The results also support the conjecture by Hau and Rey (2006) that the UEP phenomenon should become more prominent over time with continued equity market development and internation integration - the returns' correlations are negative at a $1 \%$ level of significant over the sample beginning in 2000 for all countries but Belgium, Spain and Norway, though the latter is a significant oil exporter. ${ }^{9}$ Cross-country excess equity - currency correlations reported in Appendix $\mathrm{C}$ demonstrate that if countries were found to have a significant negative correlation between their own currency and excess equity return, they also tend to have a significant negative relationship with excess equity returns of several other countries. On the other hand, if there was no significant negative

\footnotetext{
${ }^{9}$ The main patterns in the results are largely unchanged when results were tested using the period end data rather than the period average data. Based on the similarity in the salient features of the correlation analysis as they relate to the portfolio rebalancing story when using either end of period or period average returns, it seems reasonable to use the latter format when extending the analysis to commodity prices and examining the UEP using the factor model.
} 
relationship between the currency and the country's own excess equity returns, there is no correlation to the other OECD country's excess equity return either. This supports the use of using market factors to investigate spillovers in a multi-country setting.

\subsubsection{Currency - Commodity Return Correlation}

Correlation coefficients and associated significance levels between each country's currency return and the five categories of world commodity price returns are displayed in Table 2. In the sample covering the period prior to 2000, there is only scattered evidence of statistically significant correlations, with slightly more evidence of correlation between the commodity currencies and the sub-indices returns. In the sample covering the period post 2000, the currency - commodity return correlations are positive at the $1 \%$ level of significance for the vast majority of pairs. Japan is an exception in that an appreciation of the exchange rate is connected with negative growth in all sub-categories of commodity price returns, although the coefficients are not statistically significant. From the perspective of the commodity category, the agricultural raw materials price returns are only positively correlated with the commodity countries' currency returns and the currency returns of Sweden and the United Kingdom. It is clear that in the more recent period, the commodity countries are not unique in having a currency contemporaneously correlated with world commodity prices.

\subsubsection{Commodity - Equity Return Correlation}

Correlation coefficients and associated significance levels between each country's excess equity return and the five sub-categories of world commodity price returns are displayed in Table 3. It is difficult to draw distinctions between commodity exporters and other OECD countries regarding the equity market connections to the commodity market in either sub-sample. In the sample ending prior to 2000, the Australian, Canadian and Norwegian excess equity returns are an exception in a sense as each exhibit significant positive correlation with three of the commodity price indices. In this earlier sample, the excess equity return series of New Zealand did not exhibit a significant correlation with any sub-index return series. There is little evidence of correlation between excess equity returns and commodity price returns for the other OECD countries in the period prior to 2000. There is evidence of increased linkages in the recent sample, but for a number of countries there remains no significant relationships. 


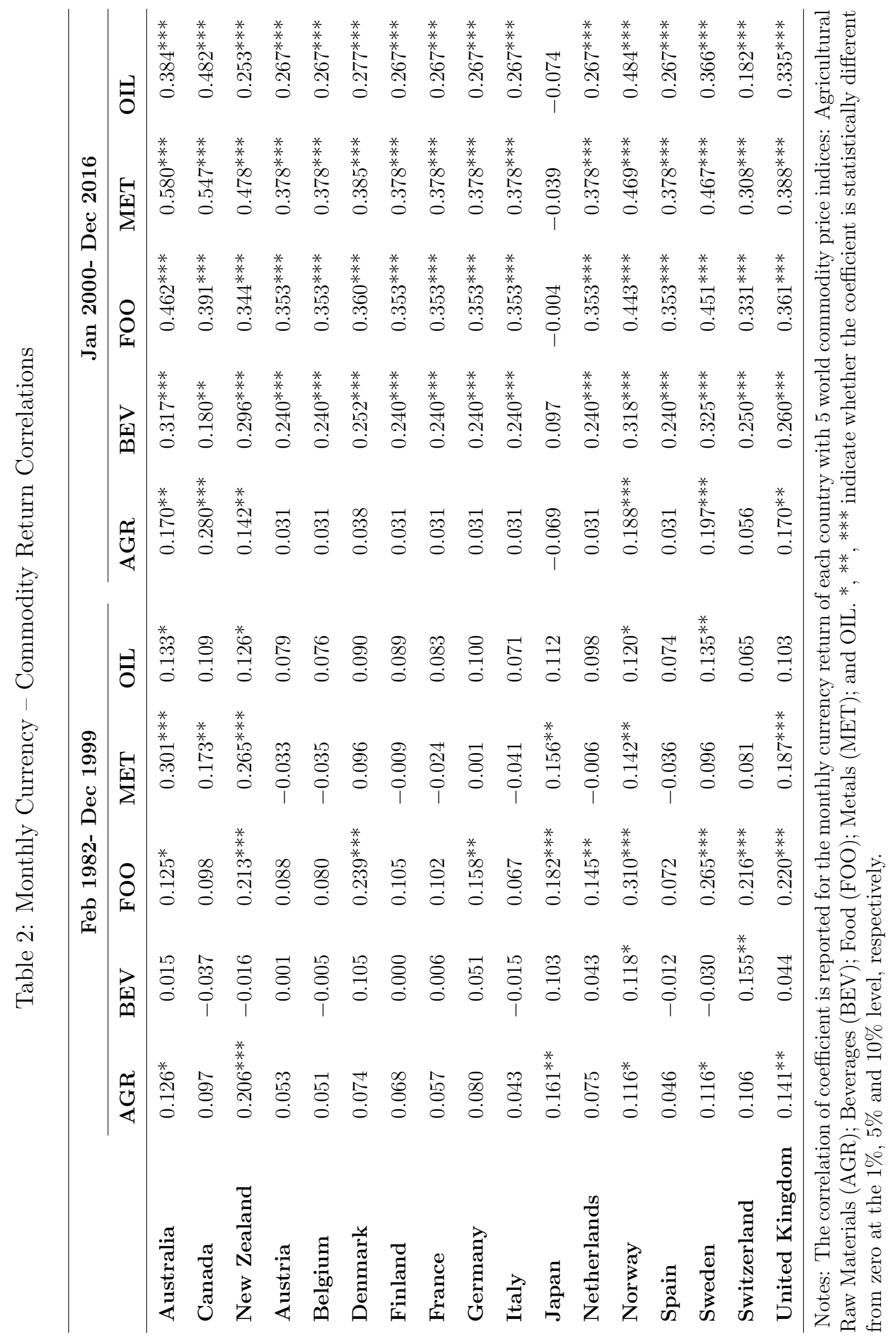




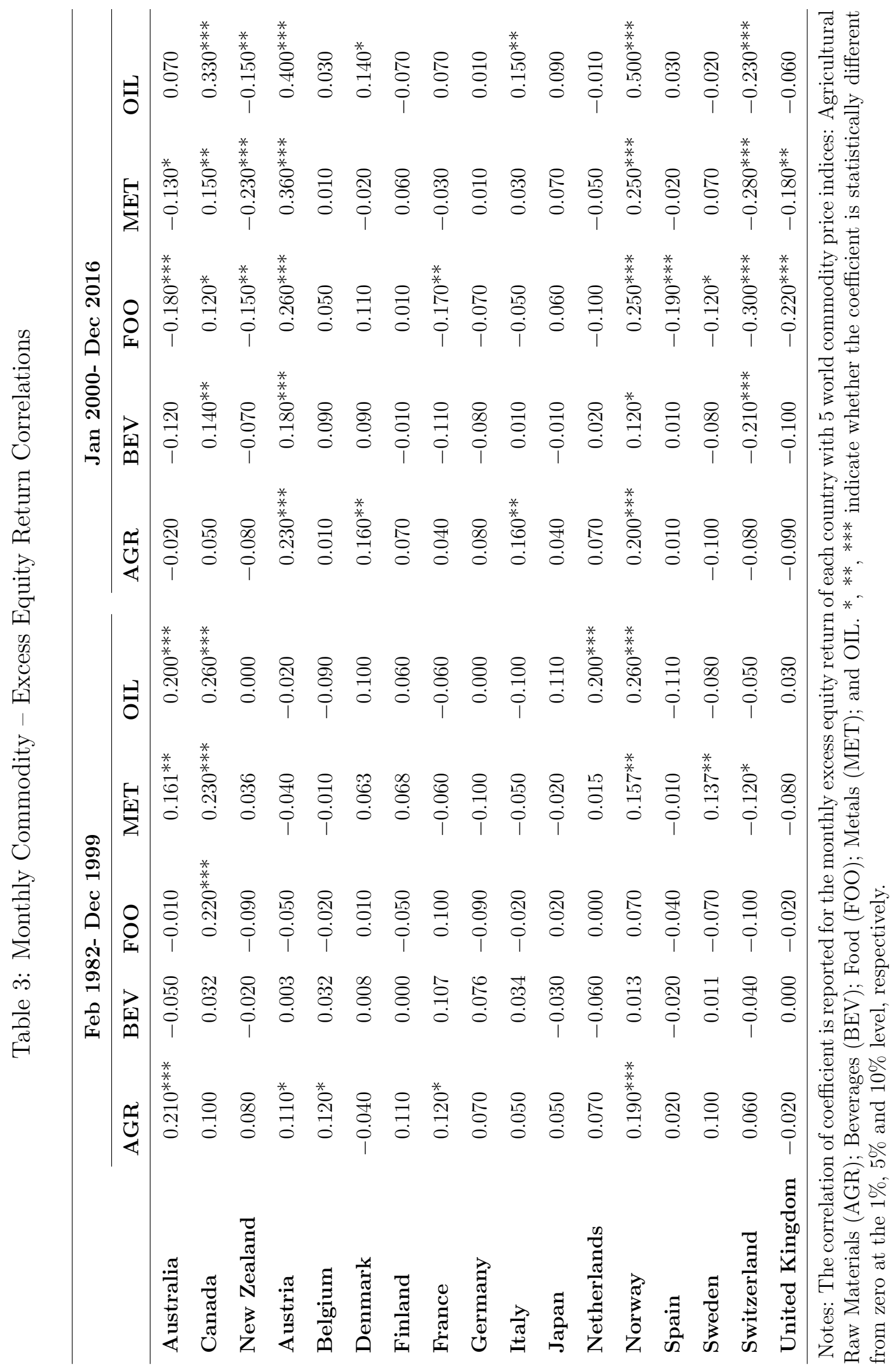




\section{Estimating The Latent Factor Models of Asset Returns}

This section presents results from estimating the latent factor model described in Section 3. The data used to estimate the factor model is as described in Section 4 and used for the preliminary analysis, however there is a slight modification to the format, which is that the absolute equity returns rather than excess returns are used for the latent factor model estimation. The US equity market is known to positively commove with international equity markets and is correlated with global business and financial cycles. Since the latent factor model is designed to capture a common global shock, important information is potentially omitted if US equity returns are filtered out. Inclusion of the US equity returns in the system helps hone in on the equity market shocks specific to the countries in the sample so that the equity factor can be interpreted as somewhat akin to an excess equity return variable.

The sample group of countries is truncated to comprise only three OECD countries for use in estimating the model used as a benchmark for the model with the three large primary commodity exporters. The correlation analysis yielded four non large commodity exporting countries for which the correlation structure between excess equity returns and currency returns is in accordance with the UEP in both periods and which have not adopted the Euro: Denmark; Sweden; Switzerland and the United Kingdom. Switzerland is dropped from this group due the currency being a safe haven currency, which may pervert the rebalancing motive. Descriptive statistics for all variables used in the latent factor analysis are contained in Appendix D. The correlation analysis affirmed the decision to split the period into two distinct samples, demarcated between December 1999 and January 2000, so the factor models for each country group are estimated over both periods accordingly.

Results obtained from estimating the latent factor model of currency, equity and commodity returns with spillovers for the three commodity countries and the three benchmark OECD countries are analysed with a focus on the importance and direction of the spillovers from cross-market factors and changes in the nature of these over time. The variance decompositions speak to the relative size of the spillover effects while the parameter estimates in conjunction with the hypothesis testing speak to the direction and significance of spillovers. The results discussed separately for the two country groups are subsequently compared and interpreted in the context of the UEP model. 


\subsection{Latent Factor Model with Large Commodity Exporters}

\subsubsection{Decomposing the Return Series}

The variance decompositions for each return series that are obtained when the factor model of large commodity exporters is estimated over the periods Feb 1982 - Dec 1999 and Jan 2000 - Dec 2016 are displayed in Panel A and Panel B of Table 4 respectively.

Table 4: Variance Decompositions for Commodity Country Latent Factor Model

\begin{tabular}{|c|c|c|c|c|c|c|c|c|}
\hline \multirow[b]{2}{*}{ Variable } & \multirow[b]{2}{*}{$\begin{array}{l}\text { Common } \\
\text { Factor }\end{array}$} & \multirow[b]{2}{*}{$\begin{array}{l}\text { Currency } \\
\text { Factor }\end{array}$} & \multirow[b]{2}{*}{$\begin{array}{l}\text { Commodity } \\
\text { Factor }\end{array}$} & \multirow[b]{2}{*}{$\begin{array}{l}\text { Equity } \\
\text { Factor }\end{array}$} & \multicolumn{3}{|c|}{ Spillovers from } & \multirow[b]{2}{*}{$\begin{array}{l}\text { Idio } \\
\text { Factor }\end{array}$} \\
\hline & & & & & $\begin{array}{l}\text { Commodity } \\
\text { Factor }\end{array}$ & $\begin{array}{l}\text { Currency } \\
\text { Factor }\end{array}$ & $\begin{array}{l}\text { Equity } \\
\text { Factor }\end{array}$ & \\
\hline & \multicolumn{8}{|c|}{ Panel A. Feb 1982 - Dec 1999} \\
\hline AUD & 0.65 & 5.10 & & & 60.34 & & 5.08 & 28.83 \\
\hline CAD & 9.46 & 11.83 & & & 6.15 & & 0.27 & 72.29 \\
\hline NZD & 0.00 & 9.13 & & & 37.77 & & 0.77 & 52.32 \\
\hline AGR & 0.09 & & 1.91 & & & 4.62 & 3.68 & 89.70 \\
\hline BEV & 0.46 & & 0.66 & & & 0.01 & 0.29 & 98.58 \\
\hline FOO & 0.39 & & 0.47 & & & 6.68 & 2.17 & 90.29 \\
\hline MET & 1.18 & & 1.04 & & & 13.01 & 0.72 & 84.05 \\
\hline OIL & 0.93 & & 0.06 & & & 23.81 & 5.45 & 69.75 \\
\hline AUE & 44.32 & & & 16.33 & 10.12 & 0.18 & & 29.05 \\
\hline CAE & 84.26 & & & 0.37 & 0.13 & 6.05 & & 9.19 \\
\hline NZE & 19.59 & & & 33.16 & 9.38 & 2.30 & & 35.56 \\
\hline \multirow[t]{2}{*}{ USE } & 81.94 & & & & & & & 18.06 \\
\hline & \multicolumn{8}{|c|}{ Panel B. Jan 2000 - Dec 2016} \\
\hline AUD & 27.31 & 66.16 & & & 5.89 & & 0.65 & 0.00 \\
\hline CAD & 27.03 & 19.20 & & & 5.34 & & 1.15 & 47.28 \\
\hline NZD & 15.21 & 43.19 & & & 5.26 & & 0.06 & 36.28 \\
\hline AGR & 7.53 & & 21.30 & & & 0.25 & 0.36 & 70.57 \\
\hline BEV & 4.47 & & 13.59 & & & 1.41 & 1.32 & 79.22 \\
\hline FOO & 4.85 & & 34.81 & & & 2.81 & 0.32 & 57.20 \\
\hline MET & 22.44 & & 15.36 & & & 0.65 & 1.72 & 59.83 \\
\hline OIL & 11.39 & & 19.79 & & & 0.06 & 5.27 & 63.49 \\
\hline AUE & 73.69 & & & 2.98 & 0.18 & 1.26 & & 21.88 \\
\hline CAE & 83.58 & & & 16.41 & 0.01 & 0.00 & & 0.00 \\
\hline NZE & 46.31 & & & 13.09 & 0.50 & 0.08 & & 40.02 \\
\hline USE & 77.15 & & & & & & & 22.85 \\
\hline
\end{tabular}

Notes: Estimates of the return volatility contribution by factor, expressed in percentage points, obtained from estimating the latent factor model for the commodity countries using return data over the two samples are reported. The currency returns are Australia (AUD); Canadia (CAD); and New Zealand (NZD). the Commodity returns are Agriculture (AGR); Beverages (BEV); food (FOO); Metals (MET); and OIL. Equity returns are Australia (AUE); Canada (CAE); New Zealand (NZE); and the United States (USE). 
Currency Returns In the early sample, the currency factor accounts for $5.1 \%$, $11.8 \%$ and $9.1 \%$ of the volatility in Australian, Canadian and New Zealand dollar returns, respectively. The idiosyncratic factor explains only $28.8 \%$ of Australian dollar variability, compared to $72.3 \%$ and $52.3 \%$ for the Canadian dollar and New Zealand dollar, respectively. The common factor accounts for less than $1 \%$ of the volatility in the Australian and New Zealand dollar returns. Given the geopolitical proximity and trade links between Canada and the US, it is unsurprising that a larger component, $9.5 \%$, of Canadian dollar return volatility is explained by the common factor. A large proportion of the return volatility of the currencies is accounted for by the lagged commodity market factor, though the extent of the spillover effect varies across countries. For Australia, the commodity factor spillover accounts for $60.3 \%$ of currency return volatility, making it the largest contributor to Australia dollar return variation. For New Zealand the figure is $37.8 \%$, and at $6.5 \%$, it is much lower for Canada. The importance of the equity market spillovers in accounting for the volatility of the currency returns is also greatest for the Australian dollar, for which the factor contributes 5.1\%, whereas the contribution to both the Canadian and New Zealand dollar returns is less than $1 \%$.

Compared to the earlier sample, a larger portion of currency return volatility is attributable to the common factor over the sample period beginning in 2000. The currency market factor also explains a higher portion of return variation for currency returns compared with the earlier sample, particularly for Australia and New Zealand, for which it accounts for $66.2 \%$ and $43.2 \%$ of return variability, respectively. At the same time, the total proportion of volatility explained by the combined effect of cross asset market spillovers falls significantly in the later sample period. Cross-market spillovers still have the largest impact on the Australian currency, but the combined contribution to volatility is only $6.5 \%$. The commodity market spillovers to the currency volatility of Australia, Canada and New Zealand are 5.9\%, 5.3\% and 5.3\% respectively and the equity market factor accounts for at most $1.2 \%$ of volatility, in the case of the Canadian dollar return.

Commodity Returns Over the early sample period, commodity price return variability is largely explained by shocks unique to each series, with the volatility contribution of the idiosyncratic factor ranging from $69.6 \%$ for oil price returns to $98.6 \%$ for beverage price returns. The common and commodity factors make relatively scarce 
contributions to each of the price index return volatilities, accounting for no more than $2 \%$ in any case. Together, spillovers from the currency and equity market comprise a reasonable portion of the commodity returns volatility. Somewhat surprisingly the currency spillover makes the greatest relative contribution to the variation in oil price returns, accounting for $23.8 \%$ of its volatility. The currency factor spillover explains $13.0 \%$ of the metal price returns volatility, $6.7 \%$ of the food price returns volatility and $4.6 \%$ of the agricultural materials price returns volatility. The equity market spillover also has the largest relative effect on the oil price returns, contributing $5.5 \%$ to volatility. The spillover from the equity factor does not play as large a role as the currency factor, accounting for $3.7 \%, 2.2 \%$ and $0.3 \%$ of volatility in agricultural, metals and food price returns, respectively. Spillovers from both currency and equity markets to beverage price returns volatility are negligible.

Over the recent sample, the common and commodity market factor become relatively more important. The common factor explains between $4.5 \%$ and $22.4 \%$ of the variation in returns for beverages and metals, respectively. However, the idiosyncratic factor still contributes the majority of volatility to all five price returns. Spillovers from either the equity or currency market factor account for less than $3 \%$ of volatility associated with commodity price returns in all instances; evidence of spillovers from the currency factor to oil and metals has disappeared.

Equity Returns The common factor explains a large component of the volatility of the equity returns, accounting for 44.3\%, 84.3\% and 19.6\% respectively for Australia, Canada and New Zealand in the early sample. The equity market factor accounts for $16.3 \%$ and $33.2 \%$ of the volatility of the Australian and New Zealand returns but only $0.4 \%$ of the Canadian return, which is unsurprising given the Canadian market is regarded as highly connected to the US market. Spillovers from the commodity market factor explain a relatively high portion of the volatility of the Australian and New Zealand equity returns, at $10.1 \%$ and $9.4 \%$ respectively but only $0.1 \%$ for Canada. In contrast, the currency factor spillover explains $6.1 \%$ of the volatility of the Canadian equity return, but only $0.2 \%$ and $2.3 \%$ for Australian and New Zealand, respectively.

In the recent sample, the common factor generally accounts for a higher portion of the Australian and New Zealand return volatility. The relative importance of the equity market factor diminishes for Australia and Canada's equity returns, falling to $3.0 \%$ and $13.1 \%$, but increases to $16.4 \%$ for Canada. Regarding cross-market effects, 
spillovers from the currency and commodity market do not account for more than $1.5 \%$ of return volatility in any case. The greatest change in this regard is the drop in the relative importance of the effect of commodity market factor on the next period equity return for Australia and New Zealand.

\subsubsection{An Overview of the Directional Impact of Asset Market Factors}

Parameter estimates along with associated standard errors for the latent factor model of the three commodity countries and the US are reported in Table 5. Panel A displays results for the Feb 1982 - Dec 1999 sample and Panel B the results from the Jan 2000 - Dec 2016 sample.

In the early sample the common factor typically affects all asset market returns in the same direction, with the exception of the oil and beverage price returns. A shock specific to each asset market drives the returns of the same asset class in the same direction. The commodity market spillover affects all equity market returns and currency market returns except for the New Zealand dollar in the same direction, which is the same direction as its contemporaneous effect on the commodity returns. The equity market spillover effects each of the currency returns with the opposite sign to its effect on the equity returns but the direction of effect to commodity returns varies by category, with a positive shock in the equity market having a negative effect on beverages, food and oil. Except for the New Zealand equity return, the currency factor spillover moves the next period equity and commodity returns in tandem with currency returns.

For the sample beginning in 2000 the effects of a shock in the common factor upon all returns and of a shock in the asset market factors upon the respective return series is similar to those seen in the early sample: a common shock moves all returns in the same direction; and an asset market shock moves returns of the same class in the same direction with the exception of an equity market shock to the Canadian equity return. The commodity market spillover again moves next period currency returns in the same direction as the commodity price returns but now moves Australian and New Zealand equity market returns in the opposite direction. The effect of the equity market factor is more difficult to decipher. A shock originating in the asset market that drives up Australian and New Zealand equity returns and drives down Canadian equity returns has a positive impact on all commodity price returns as well as the Australian and Canadian dollar. As in the early sample, a positive market shock appreciating all 
Table 5: Parameter Estimates for Commodity Country Latent Factor Model

\begin{tabular}{|c|c|c|c|c|c|c|c|c|}
\hline Variable & $\lambda$ & $\varphi$ & $\delta$ & $\kappa$ & $\beta$ & $\gamma$ & $\theta$ & $\sigma$ \\
\hline & \multicolumn{8}{|c|}{ Panel A. Feb 1982 - Dec 1999} \\
\hline \multirow[t]{2}{*}{ AUD } & 0.187 & 0.424 & & & 1.742 & & -0.503 & 1.285 \\
\hline & $(0.178)$ & $(0.262)$ & & & $(0.276)$ & & $(0.275)$ & $(0.299)$ \\
\hline \multirow[t]{2}{*}{ CAD } & 0.316 & 0.285 & & & 0.246 & & -0.051 & 0.899 \\
\hline & $(0.072)$ & $(0.077)$ & & & $-0.081)$ & & $(0.091)$ & $(0.048)$ \\
\hline \multirow[t]{2}{*}{ NZD } & 0.013 & 0.621 & & & 1.508 & & -0.214 & 1.893 \\
\hline & $(0.191)$ & $(0.229)$ & & & $(0.202)$ & & $(0.342)$ & $(0.155)$ \\
\hline \multirow[t]{2}{*}{ AGR } & 0.090 & & 0.408 & & & 0.531 & 0.563 & 2.980 \\
\hline & $(0.221)$ & & $(0.292)$ & & & $(0.248)$ & $(0.295)$ & $(0.159)$ \\
\hline \multirow[t]{2}{*}{ BEV } & -0.342 & & 0.395 & & & 0.048 & -0.263 & 5.167 \\
\hline & $(0.360)$ & & $(0.418)$ & & & $(0.449)$ & $(0.507)$ & $(0.251)$ \\
\hline \multirow[t]{2}{*}{ FOO } & 0.143 & & 0.150 & & & 0.475 & -0.321 & 2.226 \\
\hline & $(0.164)$ & & $(0.185)$ & & & $(0.208)$ & $(0.275)$ & $(0.116)$ \\
\hline \multirow[t]{2}{*}{ MET } & 0.449 & & 0.407 & & & 1.204 & -0.336 & 3.901 \\
\hline & $(0.299)$ & & $(0.330)$ & & & $(0.351)$ & $(0.490)$ & $(0.219)$ \\
\hline \multirow[t]{2}{*}{ OIL } & -0.738 & & 0.178 & & & 3.021 & 1.718 & 6.590 \\
\hline & $(0.572)$ & & $(0.626)$ & & & $(1.055)$ & $(1.064)$ & $(0.808)$ \\
\hline \multirow[t]{2}{*}{ AUE } & 3.368 & & & 1.961 & 1.553 & 0.176 & & 2.807 \\
\hline & $(0.327)$ & & & $(0.422)$ & $(0.447)$ & $(0.394)$ & & $(0.224)$ \\
\hline \multirow[t]{2}{*}{ CAE } & 3.713 & & & 0.237 & 0.143 & 0.804 & & 1.263 \\
\hline & $(0.236)$ & & & $(0.243)$ & $(0.192)$ & $(0.203)$ & & $(0.279)$ \\
\hline \multirow[t]{2}{*}{ NZE } & 2.848 & & & 3.556 & 1.902 & -0.789 & & 3.951 \\
\hline & $(0.461)$ & & & $(0.768)$ & $(0.701)$ & $(0.613)$ & & $(0.477)$ \\
\hline \multirow[t]{3}{*}{ USE } & 3.131 & & & & & & & 1.514 \\
\hline & $(0.200)$ & & & & & & & $(0.198)$ \\
\hline & \multicolumn{8}{|c|}{ Panel B. Jan 2000 - Dec 2016} \\
\hline \multirow[t]{2}{*}{ AUD } & 1.434 & 2.249 & & & 0.543 & & 0.219 & 0.000 \\
\hline & $(0.181)$ & $(0.123)$ & & & $(0.203)$ & & $(0.200)$ & $(1.83)$ \\
\hline \multirow[t]{2}{*}{ CAD } & 0.958 & 0.813 & & & 0.347 & & 0.196 & 1.337 \\
\hline & $(0.121)$ & $(0.107)$ & & & $(0.120)$ & & $(0.131)$ & $(0.068)$ \\
\hline \multirow[t]{2}{*}{ NZD } & 1.092 & 1.853 & & & 0.523 & & -0.067 & 1.780 \\
\hline & $(0.192)$ & $(0.161)$ & & & $(0.205)$ & & $(0.213)$ & $(0.089)$ \\
\hline \multirow[t]{2}{*}{ AGR } & 0.803 & & 1.101 & & & 0.146 & 0.174 & 2.595 \\
\hline & $(0.212)$ & & $(0.218)$ & & & $(0.212)$ & $(0.231)$ & $(0.155)$ \\
\hline \multirow[t]{2}{*}{ BEV } & 0.798 & & 1.135 & & & 0.452 & 0.430 & 3.548 \\
\hline & $(0.271)$ & & $(0.278)$ & & & $(0.275)$ & $(0.292)$ & $(0.196)$ \\
\hline FOO & 0.645 & & 1.409 & & & 0.495 & 0.165 & 2.338 \\
\hline & $(0.207)$ & & $(0.234)$ & & & $(0.210)$ & $(0.232)$ & $(0.187)$ \\
\hline MET & 2.129 & & 1.436 & & & 0.366 & 0.584 & -3.668 \\
\hline & $(0.309)$ & & $(0.296)$ & & & $(0.304)$ & $(0.327)$ & $(0.212)$ \\
\hline OIL & 2.770 & & 2.977 & & & 0.198 & 1.867 & 6.902 \\
\hline & $(0.576)$ & & $(0.583)$ & & & $(0.582)$ & $(0.625)$ & $(0.417)$ \\
\hline AUE & 2.896 & & & -0.577 & -0.118 & -0.382 & & 1.666 \\
\hline & $(0.200)$ & & & $(0.215)$ & $(0.171)$ & $(0.166)$ & & $(0.141)$ \\
\hline CAE & 3.309 & & & 1.453 & 0.033 & 0.005 & & 0.000 \\
\hline & $(0.208)$ & & & $(0.162)$ & $(0.185)$ & $(0.174)$ & & (1.057) \\
\hline NZE & 2.133 & & & -1.123 & -0.181 & 0.090 & & 2.092 \\
\hline & $(0.208)$ & & & $(0.225)$ & $(0.205)$ & $(0.191)$ & & $(0.158)$ \\
\hline USE & 3.229 & & & & & & & 1.855 \\
\hline & $(0.208)$ & & & & & & & $(0.115)$ \\
\hline
\end{tabular}

Notes: The maximum likelihood coefficient estimates (expressed in basis points) obtained from estimating the latent factor models for the commodity countries using return data over two sample periods are reported. Standard errors reported below parameter estimates in parentheses are based on the Hessian matrix. The currency returns are Australia (AUD); Canadia (CAD); and New Zealand (NZD). The Commodity returns are Agriculture (AGR); Beverages (BEV); food (FOO); Metals (MET); and OIL. Equity returns are Australia (AUE); Canada (CAE); New Zealand (NZE); and the United States (USE). 
currencies raises commodity prices in the next period. The same shock has a negative effect on Australian equity returns, and a positive effect on the Canadian and New Zealand equity returns.

\subsubsection{The Significance of the Spillover Channels}

The results of LR tests conducted for the seven null hypotheses for the model using the Feb 1982 - Dec 1999 sample period and the Jan 2000 - Dec 2016 sample period are displayed in Panels A and B of Table 6, respectively. Over the early sample, the null hypotheses, which involve joint tests of relevant parameter loadings being zero, can be rejected in each case with at least a $1 \%$ level of significance. For the recent sample, each hypothesis involving a restriction that the parameters on various market spillovers or combinations of spillovers are jointly zero can be rejected at the $10 \%$ level, with the exception of the null hypothesis presuming no commodity spillovers.

Table 6: Hypotheses Testing: Cross-market Spillovers in the Commodity Country Model

\section{Hypothesis - No Spillovers From:}

The currency market

The equity market

The commodity market

The commodity or currency market

The equity or commodity market

The currency or equity market

The currency, equity or commodity market

The currency market

The equity market

The commodity market

The commodity or currency market

The equity or commodity market

The currency or equity market

The currency, equity or commodity market

\section{Statistic}

Panel A. Feb 1982 - Dec 1999

29.330

0.000

32.682

0.000

19.274

0.004

47.766

0.000

48.604

0.000

62.012

0.000

76.258

0.000

Panel B. Jan 2000 - Dec 2016

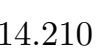

0.076

15.834

0.045

9.338

0.155

23.142

0.058

23.548

0.052

30.044

0.018

36.946

Notes: Likelihood ratio tests for the 7 null hypotheses associated with the latent factor model estimated for the commodity countries using data over two subsamples are reported. For each the null hypothesis the associated test Statistic and p-value are shown. 


\subsection{Latent Factor Model with Benchmark OECD countries}

\subsubsection{Decomposing the Return Series}

The volatility decompositions for each return series that are obtained when the factor model of the benchmark OECD countries is estimated over the periods Feb $1982-$ Dec 1999 and Jan 2000 - Dec 2016 are displayed in Panel A and Panel B of Table 7, respectively.

Table 7: Variance Decompositions for Benchmark OECD Country Latent Factor Model

\begin{tabular}{|c|c|c|c|c|c|c|c|c|}
\hline \multirow[b]{2}{*}{ Variable } & \multirow[b]{2}{*}{$\begin{array}{l}\text { Common } \\
\text { Factor }\end{array}$} & \multirow[b]{2}{*}{$\begin{array}{l}\text { Currency } \\
\text { Factor }\end{array}$} & \multirow[b]{2}{*}{$\begin{array}{l}\text { Commodity } \\
\text { Factor }\end{array}$} & \multirow[b]{2}{*}{$\begin{array}{l}\text { Equity } \\
\text { Factor }\end{array}$} & \multicolumn{3}{|c|}{ Spillovers from } & \multirow[b]{2}{*}{$\begin{array}{l}\text { Idio } \\
\text { Factor }\end{array}$} \\
\hline & & & & & $\begin{array}{l}\text { Commodity } \\
\text { Factor }\end{array}$ & $\begin{array}{l}\text { Currency } \\
\text { Factor }\end{array}$ & $\begin{array}{l}\text { Equity } \\
\text { Factor }\end{array}$ & \\
\hline & \multicolumn{8}{|c|}{ Panel A. Feb 1982 - Dec 1999} \\
\hline DEK & 3.14 & 78.99 & & & 12.87 & & 5.01 & 0.00 \\
\hline SWK & 1.02 & 24.64 & & & 43.57 & & 12.84 & 17.93 \\
\hline UKP & 0.70 & 28.92 & & & 12.64 & & 20.60 & 37.14 \\
\hline AGR & 0.01 & & 0.05 & & & 1.48 & 6.96 & 91.49 \\
\hline BEV & 1.95 & & 6.64 & & & 0.36 & 2.67 & 88.38 \\
\hline FOO & 0.05 & & 1.10 & & & 1.24 & 9.11 & 88.50 \\
\hline MET & 0.27 & & 1.28 & & & 0.17 & 25.68 & 72.61 \\
\hline OIL & 2.74 & & 0.02 & & & 0.18 & 3.76 & 93.30 \\
\hline DEE & 42.14 & & & 4.58 & 2.06 & 1.58 & & 49.65 \\
\hline SWE & 50.25 & & & 8.21 & 11.44 & 0.00 & & 30.09 \\
\hline UKE & 61.45 & & & 0.11 & 0.59 & 0.55 & & 37.30 \\
\hline \multirow[t]{2}{*}{ USE } & 71.21 & & & & & & & 28.79 \\
\hline & \multicolumn{8}{|c|}{ Panel B. Jan 2000 - Dec 2016} \\
\hline DEK & 0.98 & 0.29 & & & 5.48 & & 88.22 & 5.03 \\
\hline SWK & 8.60 & 0.07 & & & 10.50 & & 64.72 & 16.11 \\
\hline UKP & 1.07 & 0.98 & & & 13.42 & & 39.84 & 44.68 \\
\hline AGR & 3.13 & & 28.06 & & & 3.13 & 1.12 & 64.56 \\
\hline BEV & 1.60 & & 13.48 & & & 2.07 & 3.85 & 79.01 \\
\hline FOO & 1.58 & & 34.15 & & & 3.54 & 6.40 & 54.32 \\
\hline MET & 13.13 & & 21.53 & & & 0.03 & 6.37 & 58.94 \\
\hline OIL & 2.47 & & 24.95 & & & 3.29 & 3.47 & 65.83 \\
\hline DEE & 59.82 & & & 0.94 & 0.27 & 38.97 & & 0.00 \\
\hline SWE & 67.05 & & & 0.41 & 2.63 & 1.89 & & 28.02 \\
\hline UKE & 83.31 & & & 1.11 & 0.84 & 0.02 & & 14.72 \\
\hline USE & 93.07 & & & & & & & 6.93 \\
\hline
\end{tabular}

Notes: Estimates of the return volatility contribution by factor, expressed in percentage points, obtained from estimating the latent factor model for the OECD countries using return data over the two samples are reported. The currency returns are Denmark (DEK); Sweden (SWK); and United Kingdom (UKP). The Commodity returns are Agriculture (AGR); Beverages (BEV); food (FOO); Metals (MET); and OIL. Equity returns are Denmark (DEE); Sweden (SWE); United Kingdom (UKE); and the United States (USE). 
Currency Returns The common factor has a relatively small impact on currency return volatility in the early sample, accounting for at most $3.1 \%$ in the case of the Danish Krone. The currency market factor accounts for up to $79.0 \%$ of volatility in the case of the Krone, and is relatively important for the Swedish Krona and the United Kingdom Pound, accounting for $24.6 \%$ and $29.0 \%$ of volatility, respectively. Crossmarket spillovers play a large role in explaining variability in the exchange rate in the early sample; the commodity factor accounts for up to $43.6 \%$ for Sweden and the equity factor accounts for up to $20.6 \%$ for the United Kingdom.

In the recent sample, the role of the common factor remains relatively small in explaining the currency returns. The role of the market factor has fallen dramatically, not accounting for more than $1 \%$ of return variability in any case. Instead, the equity market spillover to the currency returns plays even greater role, accounting for between $39.8 \%$ and $88.2 \%$ of return variability in the case of the United Kingdom and Denmark, respectively. While the role of the commodity market spillover has diminished over time, it remains relatively important.

Commodity Returns As with the commodity country model, in the early sample the commodity returns series' volatility are overwhelmingly accounted for by the idiosyncratic factor, with the contribution ranging from $72.6 \%$ for metals and $93.3 \%$ for oil. The common factor and commodity factor explain very little of the commodity price return volatility. Spillovers from the currency factor are minimal, whereas spillovers from the equity factor are relatively large, explaining between $2.7 \%$ of beverages return volatility to $25.7 \%$ for metals returns volatility. In the recent sample the impact of cross market spillovers on commodity return volatility weakens. Instead, the commodity factor and common factor played a more important role.

Equity Returns The common factor accounts for a significant portion of equity return volatility for all the OECD benchmark countries, with the figure ranging from $42.1 \%$ for Denmark to $61.5 \%$ for the United Kingdom. The equity market factor plays a smaller role, accounting for at most $8.2 \%$ of volatility for the United Kingdom equity return. The common factor becomes an even larger determinant of equity return volatility in the recent sample, accounting for up to $83.1 \%$ of return volatility for the United Kingdom. The relative impact of the equity market factor is negligible in the recent sample. 
On the basis of relative contribution to return volatility, cross-market spillovers to the equity market are generally minimal in both sample periods. In most cases, the contribution to equity return volatility by the lagged cross-market factor is less than $3 \%$, though there are two exceptions: the commodity factor accounts for $11.4 \%$ of volatility to the Swedish equity volatility in the early sample; and the currency factor contributes $39.0 \%$ to Danish equity return volatility in the recent sample.

\subsubsection{An Overview of the Directional Impact of Asset Market Factors}

The parameter estimates for the OECD models estimated for the Feb 1982 - Dec 1999 period and the Jan 2000 - Dec 2016 period are presented in Panel A and Panel B of Table 8 respectively.

In the early period a common shock affecting all returns causes the equity and currency returns to diverge. An own market shock moves all currencies in the same direction, all but the food price index in the same direction, and the equity market of Denmark and Sweden in the same direction. A positive currency market shock that appreciates all currencies has a positive impact on the next period equity returns of Sweden and the United Kingdom and a positive impact on the commodity price returns except for agriculture. A shock to the commodity market that places upward pressure on commodity prices has a negative impact on all currency returns and a positive impact on equity returns. An equity market shock which drives up the returns of Denmark and Sweden subsequently drives up all currencies and commodity prices.

A common shock impacts all returns across the three classes in the same direction in the more recent period. The own asset market factor generally causes convergence between returns of a certain class. A positive currency market shock that appreciates the returns of Denmark and Sweden has a negative impact on equity and commodity returns in the next period. A commodity market shock causes next period currency returns to move in the same direction as the commodity returns, and equity returns the opposite direction. A positive equity market shock has positive spillover effects on all currency returns and all commodity price returns except the agricultural raw materials price index.

\subsubsection{The Significance of the Spillover Channels}

Results from the likelihood ratio tests of the joint significance of the spillovers are reported in Table 9. Panel A displays the results for the Feb 1982 - Dec 1999 sample 
Table 8: Parameter Estimates for Benchmark OECD Country Latent Factor Model

\begin{tabular}{|c|c|c|c|c|c|c|c|c|}
\hline Variable & $\lambda$ & $\varphi$ & $\delta$ & $\kappa$ & $\beta$ & $\gamma$ & $\theta$ & $\sigma$ \\
\hline & \multicolumn{8}{|c|}{ Panel A. Feb 1982 - Dec 1999} \\
\hline \multirow[t]{2}{*}{ DEK } & 0.458 & 2.289 & & & -0.764 & & 0.471 & 0.000 \\
\hline & $(0.206)$ & $(0.191)$ & & & $(0.417)$ & & $(0.325)$ & $(0.381)$ \\
\hline \multirow[t]{2}{*}{ SWK } & 0.254 & 1.238 & & & -1.362 & & 0.730 & 1.100 \\
\hline & $(0.188)$ & $(0.339)$ & & & $(0.386)$ & & $(0.350)$ & $(0.175)$ \\
\hline \multirow[t]{2}{*}{ UKP } & 0.218 & 1.388 & & & -0.759 & & 0.956 & 1.638 \\
\hline & $(0.192)$ & $(0.230)$ & & & $(0.283)$ & & $(0.296)$ & $(0.100)$ \\
\hline \multirow[t]{2}{*}{ AGR } & -0.035 & & 0.057 & & & -0.367 & 0.649 & 2.999 \\
\hline & $(0.228)$ & & $(0.263)$ & & & $(0.212)$ & $(0.226)$ & $(0.155)$ \\
\hline \multirow[t]{2}{*}{ BEV } & 0.704 & & 1.070 & & & 0.301 & 0.670 & 4.915 \\
\hline & $(0.382)$ & & $(0.411)$ & & & $(0.374)$ & $(0.468)$ & $(0.279)$ \\
\hline \multirow[t]{2}{*}{ FOO } & -0.052 & & -0.195 & & & 0.251 & 0.556 & 2.209 \\
\hline & $(0.171)$ & & $(0.179)$ & & & $(0.162)$ & $(0.193)$ & $(0.116)$ \\
\hline \multirow[t]{2}{*}{ MET } & -0.213 & & 0.384 & & & 0.168 & 1.699 & 3.644 \\
\hline & $(0.306)$ & & $(0.365)$ & & & $(0.299)$ & $(0.358)$ & $(0.237)$ \\
\hline \multirow[t]{2}{*}{ OIL } & 1.260 & & 0.096 & & & -0.319 & 1.199 & 7.619 \\
\hline & $(0.576)$ & & $(0.628)$ & & & $(0.534)$ & $(0.585)$ & $(0.386)$ \\
\hline \multirow[t]{2}{*}{ DEE } & -2.928 & & & 0.784 & 0.532 & -0.564 & & 3.293 \\
\hline & $(0.302)$ & & & $(0.301)$ & $(0.418)$ & $(0.279)$ & & $(0.190)$ \\
\hline \multirow[t]{2}{*}{ SWE } & -4.187 & & & 1.375 & 1.644 & 0.040 & & 3.357 \\
\hline & $(0.388)$ & & & $(0.442)$ & $(0.467)$ & $(0.377)$ & & $(0.291)$ \\
\hline \multirow[t]{2}{*}{ UKE } & -3.113 & & & -0.105 & 0.251 & 0.292 & & 2.514 \\
\hline & $(0.249)$ & & & $(0.223)$ & $(0.227)$ & $(0.214)$ & & $(0.171)$ \\
\hline \multirow[t]{3}{*}{ USE } & -2.900 & & & & & & & 1.911 \\
\hline & $(0.219)$ & & & & & & & $(0.188)$ \\
\hline & \multicolumn{8}{|c|}{ Panel B. Jan 2000 - Dec 2016} \\
\hline \multirow[t]{2}{*}{ DEK } & 0.230 & 0.127 & & & -0.419 & & 2.175 & 0.535 \\
\hline & $(0.170)$ & $(0.160)$ & & & $(0.171)$ & & $(0.125)$ & $(0.188)$ \\
\hline \multirow[t]{2}{*}{ SWK } & 0.754 & 0.068 & & & -0.642 & & 2.062 & -1.061 \\
\hline & $(0.181)$ & $(0.167)$ & & & $(0.169)$ & & $(0.145)$ & $(0.100)$ \\
\hline \multirow[t]{2}{*}{ UKP } & 0.221 & -0.213 & & & -0.602 & & 1.343 & 1.466 \\
\hline & $(0.156)$ & $(0.149)$ & & & $(0.142)$ & & $(0.137)$ & $(0.080)$ \\
\hline \multirow[t]{2}{*}{ AGR } & 0.533 & & -1.229 & & & -0.537 & -0.318 & 2.487 \\
\hline & $(0.215)$ & & $(0.211)$ & & & $(0.226)$ & $(0.218)$ & $(0.152)$ \\
\hline \multirow[t]{2}{*}{ BEV } & 0.492 & & -1.103 & & & -0.564 & 0.763 & 3.562 \\
\hline & $(0.280)$ & & $(0.253)$ & & & $(0.274)$ & $(0.283)$ & $(0.189)$ \\
\hline FOO & 0.380 & & -1.362 & & & -0.573 & 0.763 & 2.291 \\
\hline & $(0.210)$ & & $(0.195)$ & & & (0.198) & $(0.210)$ & $(0.154)$ \\
\hline MET & 1.655 & & -1.633 & & & -0.077 & 1.150 & -3.605 \\
\hline & $(0.317)$ & & $(0.287)$ & & & $(0.311)$ & $(0.300)$ & $(0.215)$ \\
\hline OIL & 1.327 & & -3.253 & & & -1.543 & 1.570 & 7.048 \\
\hline & $(0.603)$ & & $(0.547)$ & & & $(0.592)$ & $(0.593)$ & $(0.409)$ \\
\hline DEE & 3.721 & & & 0.464 & 0.194 & -3.025 & & 0.000 \\
\hline & $(0.295)$ & & & $(0.262)$ & $(0.239)$ & $(0.185)$ & & (1.935) \\
\hline SWE & 4.295 & & & 0.333 & 0.656 & -0.726 & & 2.855 \\
\hline & $(0.304)$ & & & $(0.240)$ & $(0.222)$ & $(0.253)$ & & $(0.159)$ \\
\hline UKE & 3.325 & & & 0.383 & 0.258 & -0.048 & & 1.437 \\
\hline & $(0.201)$ & & & $(0.126)$ & $(0.114)$ & $(0.162)$ & & $(0.125)$ \\
\hline USE & 3.641 & & & & & & & 1.022 \\
\hline & $(0.201)$ & & & & & & & $(0.197)$ \\
\hline
\end{tabular}

Notes: The maximum likelihood coefficient estimates (expressed in basis points) obtained from estimating the latent factor models for the OECD countries using return data over two sample periods are reported. Standard errors reported below parameter estimates in parentheses are based on the Hessian matrix. The currency returns are Denmark (DEK); Sweden (SWK); and United Kingdom (UKP). The Commodity returns are Agriculture (AGR); Beverages (BEV); food (FOO); Metals (MET); and OIL. Equity returns are Denmark (DEE); Sweden (SWE); United Kingdom (UKE); and the United States (USE). 
period and Panel B displays the results for the Jan 2000 - Dec 2016 sample period. Over both periods all hypotheses are rejected at the $1 \%$ level of significance, apart from the there being no equity spillovers in the early sample, which is rejected at the $5 \%$ level of significance.

Table 9: Hypotheses Testing: Cross-market Spillovers in the Benchmark OECD Country Model

\begin{tabular}{lcc}
\hline Hypothesis - No Spillovers From: & Statistic & p-value \\
\hline & Panel A. Feb 1982 & Dec 1999 \\
The currency market & 61.920 & 0.000 \\
The equity market & 15.910 & 0.044 \\
The commodity market & 32.680 & 0.000 \\
The commodity or currency market & 49.880 & 0.000 \\
The equity or commodity market & 82.560 & 0.000 \\
The currency or equity market & 91.160 & 0.000 \\
The currency, equity or commodity market & 98.040 & 0.000 \\
& Panel B. Jan $\mathbf{2 0 0 0}-\mathbf{D e c} \mathbf{2 0 1 6}$ \\
The currency market & 60.088 & 0.000 \\
The equity market & 36.134 & 0.000 \\
The commodity market & 26.796 & 0.000 \\
The commodity or currency market & 67.802 & 0.000 \\
The equity or commodity market & 93.786 & 0.000 \\
The currency or equity market & 73.486 & 0.000 \\
The currency, equity or commodity market & 111.650 & 0.000
\end{tabular}

Notes: Likelihood ratio tests for the 7 null hypotheses associated with the latent factor model estimated for the commodity countries using data over two subsamples are reported. For each the null hypothesis the associated test Statistic and p-value are shown.

\subsection{Evaluating the Portfolio Rebalancing Condition}

For both country groups, the common factor typically accounts for a larger portion of return volatility for equity and commodity prices in the sample period beginning in 2000, which is consistent with there being increased comovement across borders and asset classes. While the impact of common factor on currency returns increases slightly for the OECD countries, there is a dramatic increase in the size of the impact of the common factor on the commodity currency returns between the time periods, implying that the commodity currencies are much more integrated with world equity markets in the post 2000 era. A common shock pushes all returns in the same direction across both country groups in the recent period. In the early sample, the common shock caused OECD currency and equity returns to diverge.

Though the results of the hypothesis testing provide evidence of the importance of 
the spillover channels in both samples across both country groups, these play a less important role in the most recent sample in the case of the commodity countries as the common and market factors have played a relatively larger role in driving returns.

The UEP predicts that feedback between the currency to equity market returns is negative due to investor portfolio adjustment. There is not much evidence in support of the portfolio rebalancing mechanism for the commodity countries. In the early sample, the equity factor does cause contemporaneous equity returns and next period currency returns to move in opposite directions, however the size of the impact is small and the spillover effect from the currency to equity market returns is positive for Australia and Canada. In the recent sample, there is even less support for the UEP with relatively small feedback effects of mixed direction.

The results obtained from estimating the latent factor model using data from the benchmark OCED countries undermines the portfolio rebalancing argument. In the early sample period, there is positive bidirectional feedback between the equity and currency markets, and in the later sample there are positive spillovers from the equity market to all currency returns. In a relative sense, the impact of the currency factor spillover is minimal in both periods, and the currency market factor itself has only a small impact on currency return volatility in the recent period. The small magnitude of currency to equity market spillovers is consistent with arguments that stock portfolio rebalancing is done independently of exchange rate movements. For instance, Cenedese et al. (2015) propose that investors in reality do not consider equity and currency returns together because the equity return dwarfs the impact of currency movements. Curcuru et al. (2014) find investors don't rebalance their portfolio based on currency risk but move in to equity markets that subsequently outperform. Although it has a relatively small, though significant, effect on contemporaneous equity returns, the impact of factor isolated as driving these asset market returns on the next period currency returns is large, being particularly pronounced in the recent sample period. The equity market factor has a significantly positive impact on next period currency returns, which could be consistent with returns chasing behaviour, as international investors move in to stock markets that are performing well. Chabot et al. (2014) finds that momentum trading strategies, whereby investors buy winners and sell losers, provide abnormal profits over an early era of 1867 - 1907 and a modern era 1926 2012 . 


\subsection{Commodity Market Linkages}

The common factor explains a greater portion of return volatility for the commodity markets in the recent sample, implying they have become much more integrated with world equity markets. In the post 2000 sample, a common shock moves all returns in the same direction for both country groups.

Interestingly, the commodity market spillover to the currency market is large for both groups. For the commodity countries, bidirectional currency and commodity spillovers were positive in both directions across both periods, which is in line with the predictions of the commodity - currency model of Clements and Fry (2008). In the early period, the most notable spillover effect was from the commodity factor to the currency returns. While the commodity to currency spillover remains the most significant cross-market effect, the magnitude has diminished in the recent sample. ${ }^{10}$ For the OECD countries, the spillover had a negative effect before 2000; however, in the sample beginning in 2000, the commodity market has a positive and relativity large impact on exchange rate volatility. For the commodity countries, it is expected that since large commodity exports bring in foreign exchange, price increases lead to currency appreciations. There has been less attention on the impact of commodity prices on the exchange rates for non commodity exporters, and while the results do not shed light on the underlying transmission mechanism, it could for instance be related to spillovers from the commodity market to the economy or vice versa. Whereas the commodity currency factor had a relatively large effect on commodity price returns in the early sample, the impact of the OECD country currency market factor on commodity returns is relatively negligible in both periods.

For the large commodity exporting countries, the commodity and the equity markets appear subject to relatively large feedback effects in the early period, though the magnitude and direction of impact is mixed across returns; however, the relative importance of this channel in accounting for return volatility dissipates in the recent period. There are significant feedback effects between the world commodity market and the OECD country equity markets in the early sample; the spillover from the equity market to the commodity returns is negative, while the commodity to equity market spillover is generally positive. Though these cross-market effects are much smaller in the post 2000 sample, there are relatively large positive spillovers from the equity market to the

\footnotetext{
${ }^{10}$ This is in line with Chaban (2009), who found the role of commodity prices in explaining exchange rates falls over the sample.
} 
commodity market.

\section{Conclusion}

More commonly, there has been focus on the bivariate linkages between currency, commodity and equity returns; in contrast, this paper allows for trivariate joint dynamic interactions. The latent factor model is specified to shed light on the degree and direction of comovement and spillovers between the three asset markets, and using two country groups allows comparison between three commodity exporting countries deemed to have commodity currencies and a representative sample of three OECD countries not considered large primary commodity exporting countries.

For the commodity countries, it appears to be the integration of the currencies with world equity markets through common shocks that could interrupt the portfolio rebalancing mechanism, rather than feedback between the equity and commodity market. However, the results do not support the portfolio rebalancing channel for either country group. In fact, for the OECD countries used, there is evidence of positive spillovers from the equity market to the currency market in both sample periods, as well as positive spillovers from the currency to equity market in the pre 2000 sample. It is speculative to make assertions on the underlying cause here as this could be consistent with a number of narratives related to investor behaviour, for instance, it might imply that past stock market winners attract further funds.

The commodity countries are unique in that there are positive bidirectional spillovers between the commodity and currency market in both periods. Further, the currency market factor extracted from the model of large commodity exporters has a relatively large impact on commodity returns in the earlier sample, which speaks to the ongoing question regarding the endogeneity of commodity prices. This effect had eroded over the more recent sample period starting in 2000, however. The spillovers from the world commodity returns have a significant impact on the currency returns of the benchmark OECD countries, though in the early sample the effect was negative. There is also evidence of spillovers between commodity and equity markets for both country groups. Together, the evidence suggests that commodity prices are relevant in models of asset price determination for OECD countries in general.

Beyond the specific evidence regarding linkages, the results from the factor model estimations more generally implies that utilising simple correlations to buttress a theory regarding causative channels can be misleading. The latent factor model is useful in 
studying the interconnectedness of asset market returns as it can help disentangle notoriously conflated common market effects and cross-asset-market causative effects.

A key result is the finding of increased integration of the world commodity market with stock and currency markets; the commodity price returns load on the common factor, as well as its own market factor, to a greater extent in the post 2000 sample, which is consistent with literature examining the effect of commodity market financialisation. This has ramifications for: investors, regarding diversification for investment; producers and consumers, regarding price levels and volatilities; and policy makers who must consider the role of commodity prices in amplifying spillovers between the financial sector and the economy. 


\section{References}

Amano, R. A., \& van Norden, S. (1995). Terms of trade and real exchange rates: the Canadian evidence. Journal of International Money and Finance, 14(1), 83-104.

Basak, S., \& Pavlova, A. (2016). A model of financialization of commodities. The Journal of Finance, 71(4), 1511-1556.

Branson, W. H. (1983). A model of exchange-rate determination with policy reaction: evidence from monthly data. NBER Working paper No. w1135. Cambridge, MA: National Bureau of Economic Research.

Cashin, P., Céspedes, L. F., \& Sahay, R. (2004). Commodity currencies and the real exchange rate. Journal of Development Economics, 75(1), 239-268.

Cenedese, G., Payne, R., Sarno, L., \& Valente, G. (2015). What do stock markets tell us about exchange rates?. Review of Finance, 20(3), 1045-1080.

Chaban, M. (2009). Commodity currencies and equity flows. Journal of International Money and Finance, 28(5), 836-852.

Chabot, B., Ghysels, E., \& Jagannathan, R. (2014). Momentum trading, return chasing, and predictable crashes. NBER Working paper No. w20660. Cambridge, MA: National Bureau of Economic Research.

Chen, Y. \& Rogoff, K. (2003). Commodity currencies. Journal of international Economics, 60(1), 133-160.

Chen, Y. C., Rogoff, K. S., \& Rossi, B. (2010). Can exchange rates forecast commodity prices?. The Quarterly Journal of Economics, 125(3), 1145-1194.

Cheng, I. H., \& Xiong, W. (2014). Financialization of commodity markets.Annual Review of Financial Economics, 6(1), 419-441.

Clements, K. W., \& Fry, R. (2008). Commodity currencies and currency commodities. Resources Policy, 33(2), 55-73.

Creti, A., Joëts, M., \& Mignon, V. (2013). On the links between stock and commodity markets' volatility. Energy Economics, 37, 16-28. 
Curcuru, S. E., Thomas, C. P., Warnock, F. E., \& Wongswan, J.(2014). Uncovered equity parity and rebalancing in international portfolios. Journal of International Money and Finance, 47, 86-99.

Diebold, F. X., \& Nerlove, M. (1989). The dynamics of exchange rate volatility: a multivariate latent factor ARCH model. Journal of Applied econometrics, 4(1), 1-21.

Dornbusch, R., \& Fischer, S. (1980). Exchange rates and the current account. The American Economic Review, 70(5), 960-971.

Dungey, M. (1999). Decomposing exchange rate volatility around the Pacific Rim. Journal of Asian Economics, 10(4), 525-535.

Dungey, M., Fry, R., \& Martin, V. (2004). Currency Market Contagion in the AsiaPacific Region. Australian Economic Papers, 43(4), 379-395.

Dungey M., Fry R., González-Hermosillo B., Martin V. (2006). International contagion effects from the Russian crisis and the LTCM near-collapse. Journal of Financial Stability 2(1), 1-27.

Erb, C. B., \& Harvey, C. R. (2006). The strategic and tactical value of commodity futures. Financial Analysts Journal, 62(2), 69-97.

Frankel, J.A., 1983. Monetary and portfolio balance models of exchange rate determination. In Bhandari, J.S., Putnam, B.H. (Eds.), Economic Interdependence and Flexible Exchange Rates. MIT Press, Cambridge, MA.

Gorton, G., \& Rouwenhorst, K. G. (2006). Facts and fantasies about commodity futures. Financial Analysts Journal, 62(2), 47-68.

Hamilton, J. D. (1994). Time series analysis. Princeton, N.J: Princeton University Press.

Hau, H., \& Rey, H. (2006). Exchange rates, equity prices, and capital flows. The Review of Financial Studies, 19(1), 273-317.

Kang, W., Ratti, R. A., \& Vespignani, J. (2017). Global commodity prices and global stock volatility shocks: Effects across countries. University of Tasmania Discussion Paper Series No 2017-05. 
Kilian, L., \& Murphy, D. P. (2014). The role of inventories and speculative trading in the global market for crude oil. Journal of Applied Econometrics, 29(3), 454-478.

Kilian, L., \& Park, C. (2009). The impact of oil price shocks on the US stock market. International Economic Review, 50(4), 1267-1287.

Levich, R. M., Hayt, G. S., \& Ripston, B. A. (1998). Survey of Derivative and Risk Management Practices by U.S. Institutional Investors. Survey Conducted by the NYU Salomon Center. CIBC World Markets and EPMG

Mensi, W., Beljid, M., Boubaker, A., \& Managi, S. (2013). Correlations and volatility spillovers across commodity and stock markets: Linking energies, food, and gold. Economic Modelling, 32, 15-22.

Ng, V., Engle, R. F., \& Rothschild, M. (1992). A multi-dynamic-factor model for stock returns. Journal of Econometrics, 52(1-2), 245-266.

Pavlova, A., \& Rigobon, R. (2007). Asset prices and exchange rates. The Review of Financial Studies, 20(4), 1139-1180.

Ridler, D., \& Yandle, C. A. (1972). A simplified method for analyzing the effects of exchange rate changes on exports of a primary commodity. IMF Staff Papers, 19(3), 559-578.

Sargent, T. J., \& Sims, C. A. (1977). Business cycle modeling without pretending to have too much a priori economic theory. New methods in business cycle research, 1 , 145-168.

Silvennoinen, A., \& Thorp, S. (2013). Financialization, crisis and commodity correlation dynamics. Journal of International Financial Markets, Institutions and Money, 24, 42-65.

Tang, K., \& Xiong, W. (2012). Index investment and the financialization of commodities. Financial Analysts Journal, 68(6), 54-74. 


\section{Appendix A Lag selection}

Table A1: Lag Selection Criteria of a VAR of Currency and Commodity and Equity Returns

\begin{tabular}{cccl}
\hline Lag & Log L & LR & AIC \\
\hline \multicolumn{4}{c}{ Panel A. Commodity country model } \\
2 & -12407.800 & 425.288 & $60.548^{*}$ \\
2 & -12301.200 & 200.366 & 60.729 \\
3 & -12198.300 & $187.401^{*}$ & 60.927 \\
4 & -12108.700 & 158.076 & 61.189 \\
& Panel B. OECD benchmark model & & \\
1 & -12466.100 & 476.295 & $60.829^{*}$ \\
2 & -12365.200 & $189.764^{*}$ & 61.037 \\
3 & -12282.300 & 150.908 & 61.332 \\
4 & -12195.100 & 153.830 & 61.605 \\
\hline
\end{tabular}

Notes: Results from the various lag selection tests for both the commodity country and OECD benchmark model are reported in Panel A and Panel B respectively. LR is the sequential modified Likelihood Ratio test statistic; and AIC is the Akaike information criterion. Each test is at the 5\% level. * denotes the lag order selected by the criteria. 


\section{Appendix B Data}

Table B1: Data and Sample Description

\begin{tabular}{ll}
\hline Name & Description \\
\hline Commodity Price Index & $\begin{array}{l}\text { Commodity Price index in US dollar terms, calculated as period average } \\
\text { Exchange rate in terms of US dollars per national currency, calculated } \\
\text { as period average }\end{array}$ \\
Equity Price Index & Equity Price Index in US dollar terms, end of day \\
\hline
\end{tabular}

Table B2: Datastream Source Codes

\begin{tabular}{|c|c|c|c|c|}
\hline \multicolumn{3}{|c|}{ Currency and Equity Indices } & \multicolumn{2}{|c|}{ Commodity Data } \\
\hline Country & $\begin{array}{l}\text { Currency } \\
\text { Indices }\end{array}$ & Equity Indices & Category & $\begin{array}{l}\text { Commodity } \\
\text { Indices }\end{array}$ \\
\hline Australia & AUI..AH. & MSAUSTL(PI) & Agricultural Raw Materials & WDI76BXDF \\
\hline Austria & OEI..AH. & MSASTRL(PI) & Beverages & WDI76DWDF \\
\hline Belgium & BGI..AH. & MSBELGL(PI) & Food & WDI76EXDF \\
\hline Canada & CNI..AH. & MSCNDAL(PI) & Metals & WDI76AYDF \\
\hline Denmark & DKI..AH. & MSDNMKL(PI) & Oil & USI76AADF \\
\hline Finland & FNI..AH. & MSFINDL(PI) & & \\
\hline France & FRI..AH. & MSFRNCL(PI) & & \\
\hline Germany & DEI..AH. & MSGERML(PI) & & \\
\hline Italy & ITI..AH. & MSITALL(PI) & & \\
\hline Japan & JPI..AH. & MSJPANL(PI) & & \\
\hline Netherlands & NLI..AH. & MSNETHL(PI) & & \\
\hline New Zealand & NZI..AH. & MSNZEAL(PI) & & \\
\hline Norway & NOI..AH. & MSNWAYL(PI) & & \\
\hline Spain & ESI..AH. & MSSPANL(PI) & & \\
\hline Sweden & SDI..AH. & MSSWDNL(PI) & & \\
\hline Switzerland & SWI..AH. & MSSWITL(PI) & & \\
\hline United Kingdom & UKI..AH. & MSUTDKL(PI) & & \\
\hline United States & & MSUSAML(PI) & & \\
\hline
\end{tabular}


Table B3: List of Sample Countries

\begin{tabular}{|c|c|c|}
\hline Country & Included in Hau and Rey (2006) Sample & Included in Sample \\
\hline Australia & yes & yes \\
\hline Austria & yes & yes \\
\hline Belgium - Luxembourg & yes & yes \\
\hline Canada & no & yes \\
\hline Denmark & yes & yes \\
\hline Finland & yes & yes \\
\hline France & yes & yes \\
\hline Germany & yes & yes \\
\hline Greece & no & no \\
\hline Iceland & no & no \\
\hline Ireland & yes & yes \\
\hline Italy & yes & yes \\
\hline Japan & yes & yes \\
\hline Luxembourg & yes & yes \\
\hline Netherlands & yes & yes \\
\hline New Zealand & no & yes \\
\hline Norway & yes & yes \\
\hline Portugal & yes & yes \\
\hline Spain & yes & yes \\
\hline Sweden & yes & yes \\
\hline Switzerland & yes & yes \\
\hline Turkey & no & no \\
\hline United Kingdom & yes & yes \\
\hline United States & yes & yes \\
\hline
\end{tabular}

Notes: This table is a list of all countries that were OECD members at the start of the sample period used in Hau and Rey (2006) and indicates whether they were used in that sample and the sample in this paper. 


\section{Appendix C Cross Country Equity-Currency Re- turn Correlation}

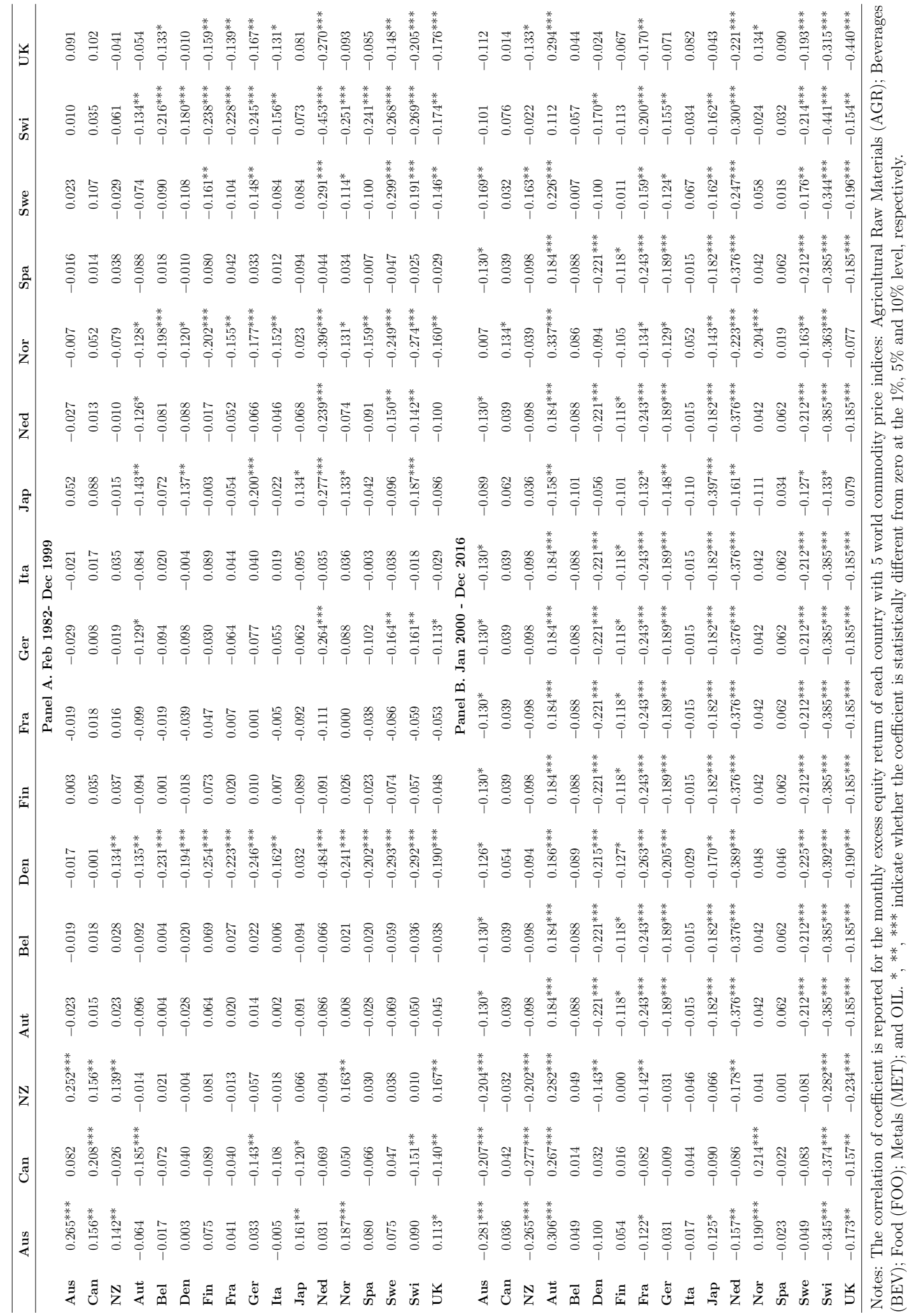




\section{Appendix D Descriptive Statistics}

Table D1: Descriptive Statistics for Demeaned Monthly Return Variables Used in Factor Models

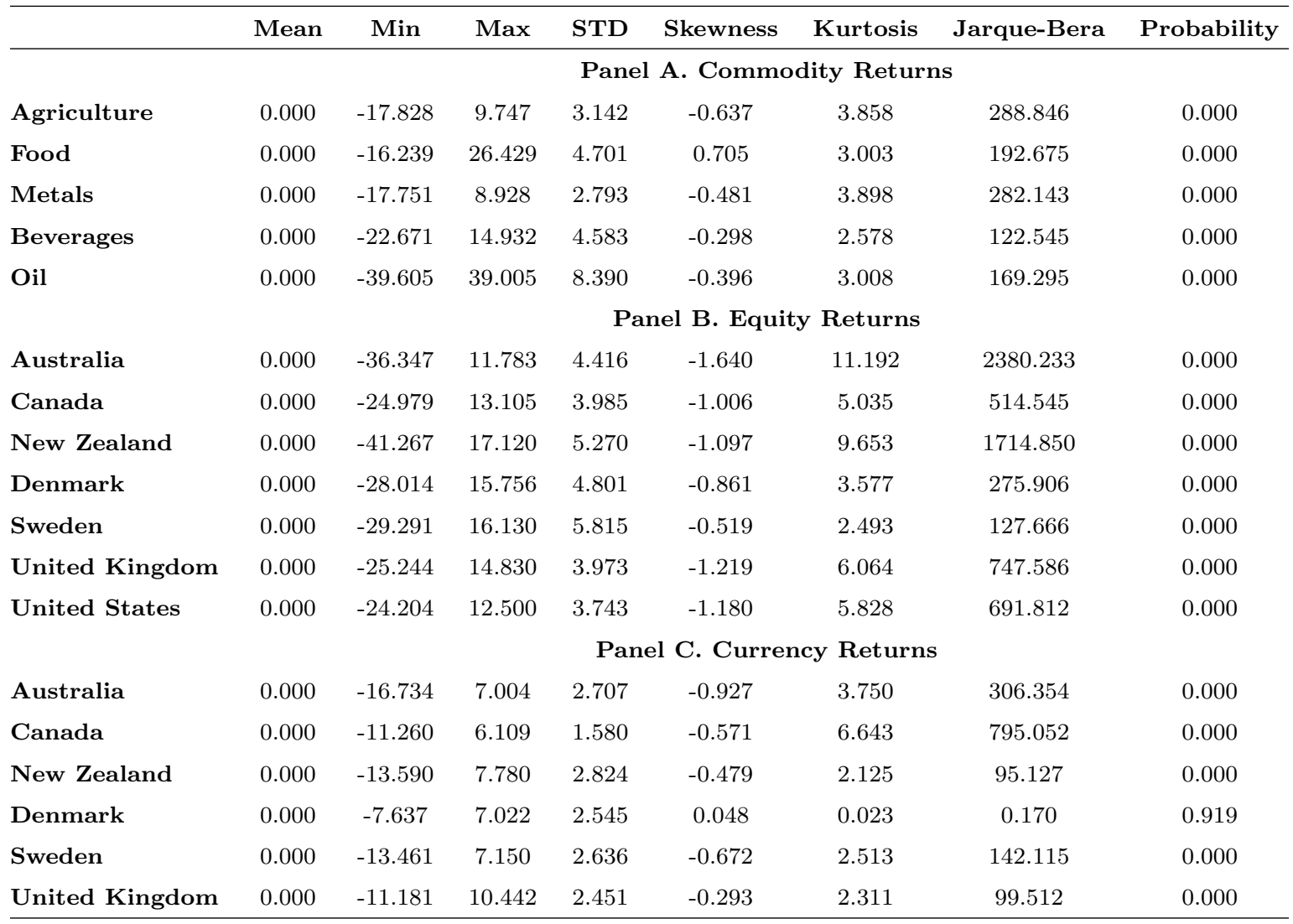

